\title{
Host-induced aneuploidy and phenotypic diversification in the Sudden Oak Death pathogen Phytophthora ramorum
}

\author{
Takao Kasuga', Mai Bui ${ }^{1}$, Elizabeth Bernhardt ${ }^{2}$, Tedmund Swiecki ${ }^{2}$, Kamyar Aram³ ${ }^{3}$, Liliana M. Cano ${ }^{4}$, Joan Webber ${ }^{5}$,
} Clive Brasier ${ }^{5}$, Caroline Press ${ }^{6}$, Niklaus J. Grünwald ${ }^{6}$, David M. Rizzo ${ }^{3}$ and Matteo Garbelotto ${ }^{7 *}$

\begin{abstract}
Background: Aneuploidy can result in significant phenotypic changes, which can sometimes be selectively advantageous. For example, aneuploidy confers resistance to antifungal drugs in human pathogenic fungi. Aneuploidy has also been observed in invasive fungal and oomycete plant pathogens in the field. Environments conducive to the generation of aneuploids, the underlying genetic mechanisms, and the contribution of aneuploidy to invasiveness are underexplored. We studied phenotypic diversification and associated genome changes in Phytophthora ramorum, a highly destructive oomycete pathogen with a wide host-range that causes Sudden Oak Death in western North America and Sudden Larch Death in the UK. Introduced populations of the pathogen are exclusively clonal. In California, oak (Quercus spp.) isolates obtained from trunk cankers frequently exhibit host-dependent, atypical phenotypes called non-wild type $(n w t)$, apparently without any host-associated population differentiation. Based on a large survey of genotypes from different hosts, we previously hypothesized that the environment in oak cankers may be responsible for the observed phenotypic diversification in $P$. ramorum.

Results: We show that both normal wild type (wt) and nwt phenotypes were obtained when wt P. ramorum isolates from the foliar host California bay (Umbellularia californica) were re-isolated from cankers of artificially-inoculated canyon live oak (Q. chrysolepis). We also found comparable nwt phenotypes in $P$. ramorum isolates from a bark canker of Lawson cypress (Chamaecyparis lawsoniana) in the UK; previously nwt was not known to occur in this pathogen population. High-throughput sequencing-based analyses identified major genomic alterations including partial aneuploidy and copy-neutral loss of heterozygosity predominantly in nwt isolates. Chromosomal breakpoints were located at or near transposons.

Conclusion: This work demonstrates that major genome alterations of a pathogen can be induced by its host species. This is an undocumented type of plant-microbe interaction, and its contribution to pathogen evolution is yet to be investigated, but one of the potential collateral effects of nwt phenotypes may be host survival.
\end{abstract}

Keywords: Invasive pathogens, Aneuploidy, Transposable elements, Loss of heterozygosity

\section{Background}

A growing number of studies have shown that non-native species are able to evolve rapidly following introduction into a new region (reviewed in [1]). Introduced species may be subject to "episodic selection", i.e. rapid genetic and phenotypic changes possibly leading to incipient speciation

\footnotetext{
* Correspondence: matteog@berkeley.edu

${ }^{7}$ Department of Environmental Science, Policy, and Management, University of California, Berkeley, California 947020, USA

Full list of author information is available at the end of the article
}

caused by sudden and intense environmental disturbance [2]. The concept of "accelerated evolution" may involve two processes: rapid phenotypic change of a particular trait due to differential selective pressure on existing genetic variation, or the generation of de novo phenotypic variation in environments where the organism is poorly adapted [3]. De novo mutation and mitotic recombination probably account for the rapid phenotypic diversification observed in many introduced fungal pathogens lacking initial genetic diversity, including oomycetes $[4,5]$. 
To date, most mechanisms responsible for de novo mutation remain elusive. Aneuploidy, the loss or gain of chromosomes in a nucleus, is frequently generated and can create substantial variation in gene expression by effectively altering gene dosage. Aneuploidy is thus a potentially effective and widespread mechanism for developing novel phenotypic variation in a clonal population [6-8]. For example, antifungal drug resistance in several human pathogenic fungi has been attributed to aneuploidy [9].

In this study, we employed high throughput sequencing to characterize genomic diversity underlying rapid phenotypic diversification in the clonal organism Phytophthora ramorum. $P$. ramorum is the exotic oomycete pathogen responsible for Sudden Oak Death in North America [10], Sudden Larch Death in the UK and Ireland [11], and Ramorum Blight in the nursery trade both in North America and Europe $[12,13]$. Its origin is still unknown, but four distinct clonal lineages have been identified. The lineages are believed to have originated from distinct genetically isolated populations in their (presently unknown) region of origin [14]. The NA1, NA2, and to a lesser degree the EU1 lineages are present in North American plant nurseries, while only the EU1 and EU2 lineages are found in Europe [15-17]. Only the NA1 lineage has escaped into natural forest settings on the West Coast of California, where it causes the disease known as Sudden Oak Death $[15,18]$. In oaks, disease is caused by lethal trunk cankers, which do not extend below ground [10].

Despite being clonal, isolates of the NA1 lineage display striking variation in colony morphology and growth rate not readily observed in the other lineages. In culture, wild type (wt) $P$. ramorum usually grows as a uniform, roughly circular colony mostly appressed to the culture media [19]. However, some NA1 isolates exhibit irregular, unstable, usually slower growing and "fluffy" colony types, referred to as non-wild type (nwt). Some nwt isolates become senescent, i.e. they cease to grow upon subculturing. Inoculation experiments have shown that isolates with $n w t$ morphology are less aggressive than $w t$ isolates [19-21].

Recently, we have demonstrated that $P$. ramorum isolates originating from trunks of oak (Quercus spp.) are more likely to show $n w t$ and senescent phenotypes than those from foliage of California bay (Umbellularia californica) [21]. Transcriptome analysis revealed that de-repression of hundreds of transposable elements (TEs) and down-regulation of Crinkler effector homologs (but no other effector families) were common in oak isolates, yet this expression pattern was never observed in isolates from California bay. Our finding of phenotypic differences between isolates from oak and California bay is significant in the context of Sudden Oak Death. It has been demonstrated that oak is a dead-end host with oak infection initiated only via asexual airborne propagules from nearby foliar hosts, most importantly California bay, which does not develop trunk cankers [22, 23]. Consistent with this view, microsatellite markers did not reveal any genetic subdivision between isolates from California bay and oak hosts [21].

Together these observations lead us to hypothesize that in oak, $P$. ramorum undergoes phenotypic diversification after infection. This process could be termed host-induced phenotypic diversification (HIPD) because the observed phenotypic changes are host species-dependent. In our case, HIPD is commonly associated with oak, rarely with tanoak, and is virtually absent in bay or Rhododendron. To our knowledge phenomena similar to HIPD have not been reported in the literature. However, the putative de novo phenotypic variation observed among oak isolates and their reduced aggressiveness [19-21] could be comparable to the increased accumulation of deleterious mutations reported for zoonotic viruses and intercellular symbiotic bacteria when horizontal transmission between hosts was restricted $[24,25]$. In this sense, HIPD could be compatible with the current view that oak is a dead-end host for P. ramorum. This view appears reasonable in light of the fact that sporulation of $P$. ramorum from oak bark has yet to be observed.

In this study, we attempt to establish direct evidence of the nature of HIPD and of its genetic basis through the artificial inoculation of NA1 isolates on different hosts. We were able to experimentally recreate HIPD, and subsequently through high throughput sequencing-based methods we demonstrated that aneuploidy was associated with HIPD. Although EU1 isolates of P. ramorum lineage have exclusively shown $w t$ colony morphology [19], EU1 isolates with $n w t$ colony morphology have recently been obtained from a rare host, Lawson cypress (Chamaecyparis lawsoniana; also known as Port Orford Cedar). We show that these are due to similar chromosomal rearrangements. The observation of HIPD in two distinct evolutionary lineages of $P$. ramorum further emphasizes its potential biological and epidemiological significance.

\section{Results}

\section{Scoring for wt and nwt colony morphology}

Some $w t$ cultures developed into $n w t$ colonies upon subculturing [19]. For example, when a culture of oak isolate Pr-102 showing $w t$ morphology was subcultured, 29 out of 100 colonies displayed $n w t$ morphology within seven days (Petri plate control in Table 1, Additional file 1). Additionally, some Pr-102 nwt cultures also became senescent. In contrast, NA1 isolates from foliar hosts consistently displayed homogenous wt colony type as demonstrated by the fact that no $n w t$ was observed out of a total of 348 subcultures. Nwt morphology was significantly more common in Pr-102 than in isolates from foliar hosts (Fisher's exact test $p=2.2 \times 10^{-16}$ ). When $n w t$ colony morphology was observed upon further 
Table 1 Summary of phenotypic conversion upon passage experiments

\begin{tabular}{|c|c|c|c|c|c|}
\hline \multirow[t]{2}{*}{ Inoculated host, year } & \multirow[t]{2}{*}{ \# Trees (\# Leaves) } & \multirow[t]{2}{*}{ Inoculum; duration in host } & \multicolumn{2}{|c|}{ Phenotypes $^{f}$} & \multirow[t]{2}{*}{ Tota } \\
\hline & & & $w t$ & $n w t$ & \\
\hline \multirow[t]{2}{*}{ Petri plate control } & $\mathrm{n} / \mathrm{a}$ & $\begin{array}{l}\text { Pr-710, Pr-745, Pr-1556, Pr-1557, } \\
\text { ND886 (wt, foliar hosts) }{ }^{\mathrm{b}} ; \mathrm{n} / \mathrm{a}\end{array}$ & 348 & 0 & 348 \\
\hline & $\mathrm{n} / \mathrm{a}$ & $\operatorname{Pr}-102(n w t, \text { oak })^{c} ; n / a$ & 71 & 29 & 100 \\
\hline \multirow[t]{2}{*}{ Canyon live oak, 2010} & 8 & Pr-710 and Pr-745 (wt, bay); 20 weeks & 37 & 25 & 62 \\
\hline & 10 & $\operatorname{Pr}-710$ and $\operatorname{Pr}-745$ ( $w t$, bay); 40 weeks & 23 & 35 & 58 \\
\hline Shreve oak, 2010 & 2 & Pr-710 and Pr-745 (wt, bay); 20 weeks & 6 & 2 & 8 \\
\hline Canyon live oak, 2012 & 4 & Pr-1556 and Pr-1557 (wt, bay); 20 weeks & $27^{d}$ & 0 & 27 \\
\hline California bay, 2012 & $1(9)$ & $\operatorname{Pr}-745$ (wt, bay); 20 weeks & 9 & 0 & 9 \\
\hline \multirow[t]{2}{*}{ California bay, 2013} & $3(27)$ & ND886 (wt, camellia); 4 to 25 weeks $^{\mathrm{e}}$ & 20 & 0 & 20 \\
\hline & $3(27)$ & Pr-102 (nwt, oak); 4 to 25 weeks ${ }^{\mathrm{e}}$ & 16 & 2 & 18 \\
\hline
\end{tabular}

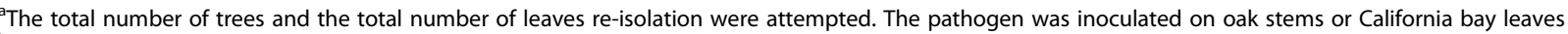

${ }^{b}$ colony morphology of five $w t$ isolates grown on Petri plates was scored. 24, 24, 100, 100 and 100 replicates were made for Pr-710, Pr-745, Pr-1556, Pr-1557, and ND886, respectively

${ }^{\mathrm{C}} \mathrm{Pr}$-102 displaying wt colony morphology was used as inoculum. The 71 subcultures showing wt morphology were expected to display nwt colony morphology at a certain percentage upon subsequent subculturing

${ }^{\mathrm{d}}$ Most of the tested $w t$ isolates displayed nwt after passage through race tubes

${ }^{e}$ re-isolation was made 4, 12 and 25 weeks post-inoculation

${ }^{\mathrm{f}}$ Criteria for scoring of $w t / n w t$ are described in Evaluation of colony morphology in Methods

subculturing, we assigned the original isolate to the $n w t$ phenotype, even if the original isolate did not consistently display $n w t$ colony morphology. Thus, $n w t$ colony phenotype in this study was defined as the ability to develop the $n w t$ morphology upon subculturing. To track this phenomenon, we precisely indicate [21] colony phenotypes and the known history for each isolate in our results (Additional file 2). For example, Pr-1556\#7\#1 (nwt, bay $\rightarrow$ oak $\rightarrow$ race tube) indicates isolate of $\mathrm{Pr}-1556 \# 7 \# 1$ was originally isolated from a California bay and subsequently passed through oak via an artificial inoculation, and then transferred to, and recovered from a race tube.

\section{Experimental generation of phenotypes associated with oak isolates}

We hypothesized that the oak host environment in which $P$. ramorum grows induces HIPD. In order to experimentally demonstrate HIPD, phenotypic changes during host passage experiments were monitored. Two passage experiments were conducted on oak using four California bay isolates as inocula. In the first passage experiment, two $w t$ P. ramorum isolates, Pr-710 (wt, bay) and Pr-745 (wt, bay - isolated from rainwater adjacent to infected California bays), were inoculated into stems of mature canyon live oak (Q. chrysolepis) and Shreve oak (Q. parvula var. shrevei) in July 2010 [26]. In December 2010 and April 2011, 20 and 40 weeks post-inoculation, respectively, the pathogen was re-isolated from lesions that had formed in the phloem and underlying xylem (Fig. 1). These are termed "re-isolates" hereafter. Thirty-nine percent of re-isolates collected 20 weeks post-inoculation (of 70 from canyon live oak and Shreve oak combined) and $60 \%$ collected 40 weeks (of 58 from canyon live oak only) were assigned to $n w t$ phenotype. In contrast, none of 48 in vitro subcultures of isolates Pr-710 and Pr-745 displayed nwt phenotype (Petri plate control in Table 1).

In order to obtain baseline phenotypic conversion rate in foliar hosts, California bay leaves were inoculated with
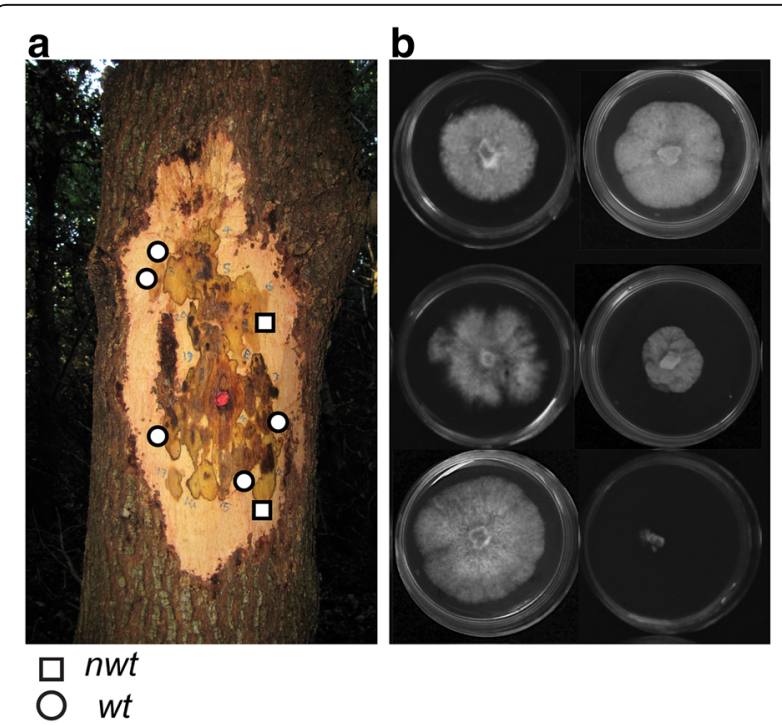

Fig. 1 Nwt colony phenotype was experimentally reproducible by oak passage experiment. a Scraping off the outer bark 20 weeks post-inoculation revealed diseased tissue. The red mark at the center indicates the inoculation point. Isolates recovered from circle and square marks yielded wt and nwt colonies, respectively. $\mathbf{b}$ Isolates show diverse colony morphology. Top left: Pr-745 ( $w t$, bay), top right: Pr-710 (wt, bay), both are wild type isolates used as inocula. Middle left and right: examples of re-isolates from canyon live oak showing nwt colony morphology. Bottom left: a re-isolate from canyon live oak showing a wt colony morphology, bottom right: an example of early senescence 
two $w t$ isolates, Pr-745 (wt, bay) and ND886 (wt, camellia), and re-isolate phenotypes were evaluated. None of the 29 re-isolates derived over 25 weeks from $\operatorname{Pr}-745$ and ND886 inoculations showed nwt morphology. Together this series of passage experiments indicate that canyon live oak and Shreve oak, but not California bay, induced phenotypic conversion from $w t$ to $n w t$; therefore, we conclude that HIPD is experimentally reproducible. In addition, the $n w t$ isolate Pr102 was passed through California bay to evaluate the potential reversibility of $n w t$ colony phenotype by epigenetics or phenotypic plasticity. However, we failed to detect the reversibility with certainty: two out of 18 (11\%) re-isolates derived from Pr102 displayed nwt colony morphology, which did not differ significantly (Fisher's exact test $p=0.3$ ) from the rate of $n w t$ morphology observed for in vitro subcultures (29 nwt out of 100, Table 1).

The oak inoculation experiment was repeated with different isolates, Pr-1556 and Pr-1557 (wt, bay) in July 2012. In December 2012 (20 weeks post-inoculation), 27 axenic cultures of Pr-1556 and Pr-1557 were re-isolated from phloem tissue of resulting cankers (Table 1). Contrary to the first passage experiment, no isolates with $n w t$ morphology or senescence were observed at the moment they were cultured out of the hosts in which they were inoculated. However, punctuated growth patterns, one of the common characteristics of the $n w t$ phenotype, were observed 10 to 16 weeks after they were placed in race tubes and monitored (see below).

\section{Validation of experimentally induced phenotypic conversion by means of global mRNA profiling}

Re-isolates and isolates from naturally infected oak with $n w t$ phenotype were morphologically indistinguishable. We have previously reported that $w t$ and $n w t$ isolates show distinct global mRNA patterns [21], indicating physiological differences associated with the colony types. In order to validate the experimental induction of HIPD, we performed global mRNA profiling for the two isolates $\operatorname{Pr}-710$ (wt, bay) and Pr-745 (wt, bay) used in the oak passage experiment and five re-isolates with $w t$ or $n w t$ colony types (Fig. 2). Pr-102 (nwt, oak), an isolate derived from a naturally infected oak exhibiting a distinct global mRNA expression pattern associated with $n w t$ phenotype [21] was included in the analysis as a " $n w t$ standard". Cluster analysis of global mRNA profiles revealed two major groups, each associated with a specific colony phenotype. The two $w t$ isolates used in the inoculation trial and two re-isolates showing $w t$ phenotype formed one group (Group A in Fig. 2a), while the three re-isolates showing $n w t$ phenotype plus Pr-102 formed the other group (Group B). Hence, global mRNA profiling corroborates that isolates with $n w t$ phenotype are physiologically equivalent whether obtained directly from naturally infected trees or obtained from artificially inoculated oak.
De-repression of transposable elements (TEs), a hallmark of the $n w t$ phenotype, was observed in the three $n w t$ reisolates (Fig. 2b). In addition, down-regulation of Crinkler effector homologs, which was common in oak isolates, was observed in two $n w t$ re-isolates derived from $\operatorname{Pr}-745$. We have therefore experimentally established that the $n w t$ phenotype is generated in oak.

\section{Re-isolates showed accelerated growth rate in race tubes} None of the 27 Pr-1556 and Pr-1557 (wt, bay-> oak) reisolates obtained in the second oak passage experiment initially had a $n w t$ phenotype. Among the re-isolates in the first oak passage experiment, $w t$ re-isolates occasionally displayed nwt morphology on subsequent subculturing, suggesting $n w t$ phenotype can be latent and develop during continued cultivation on artificial media. Although no nwt colony morphology was observed among isolates in the second passage experiment, we hypothesized the likelihood of $w t$ to $n w t$ conversion would be elevated in the re-isolates from oaks. In order to address this possibility, three transfers each were made from four re-isolates from the second oak passage experiment, the two original isolates, and a camellia isolate, onto $40 \mathrm{~cm}$-long race tubes. Growth rates were monitored once a week (Fig. 3). In the course of 18 weeks, Pr-1556 (wt, bay) and Pr-1557 (wt, bay) displayed consistent growth rates (Fig. 3a, b), while growth rates of $w t$ re-isolates from oaks (Fig. 3c, d) accelerated or decelerated considerably after 10 weeks. The accelerated growth rate observed in re-isolates is hereafter referred to as growth acceleration phenotype (GAP). In the race tube, the hyphal tips at the growing front do not always extend at the same rate: the fastestgrowing hyphal tip can ramify, expand and take over the colony front. In other words, a fast growing trait can be selected when variation in growth rates of individual hyphal tips occurs, which is likely the case for GAP.

All cultures were transferred back to duplicate Petri plates once the mycelial fronts reached the far end of race tubes. In total, three of the four original re-isolates showed $n w t$ or senescent colony types in at least one replicate after recovery from the race tubes (Table 2). In contrast, none of the California bay and camellia isolates showed $n w t$ phenotypes after recovery from race tubes (Table 2). In summary, the race tube experiment demonstrated that $w t$ re-isolates from oak have a greater or latent propensity for the conversion to $n w t$ colony morphology than foliar isolates (Fisher's exact test, $p=4.6 \times 10^{-3}$ ).

Analysis of chromosomal copy number variations (CCNVs) The results of the inoculation experiments uphold our interpretation of the mechanisms underlying HIPD, implying that the environment in oak cankers triggers de novo mutations in P. ramorum. As a potential source of the $n w t$ phenotype, we examined changes in chromosomal 


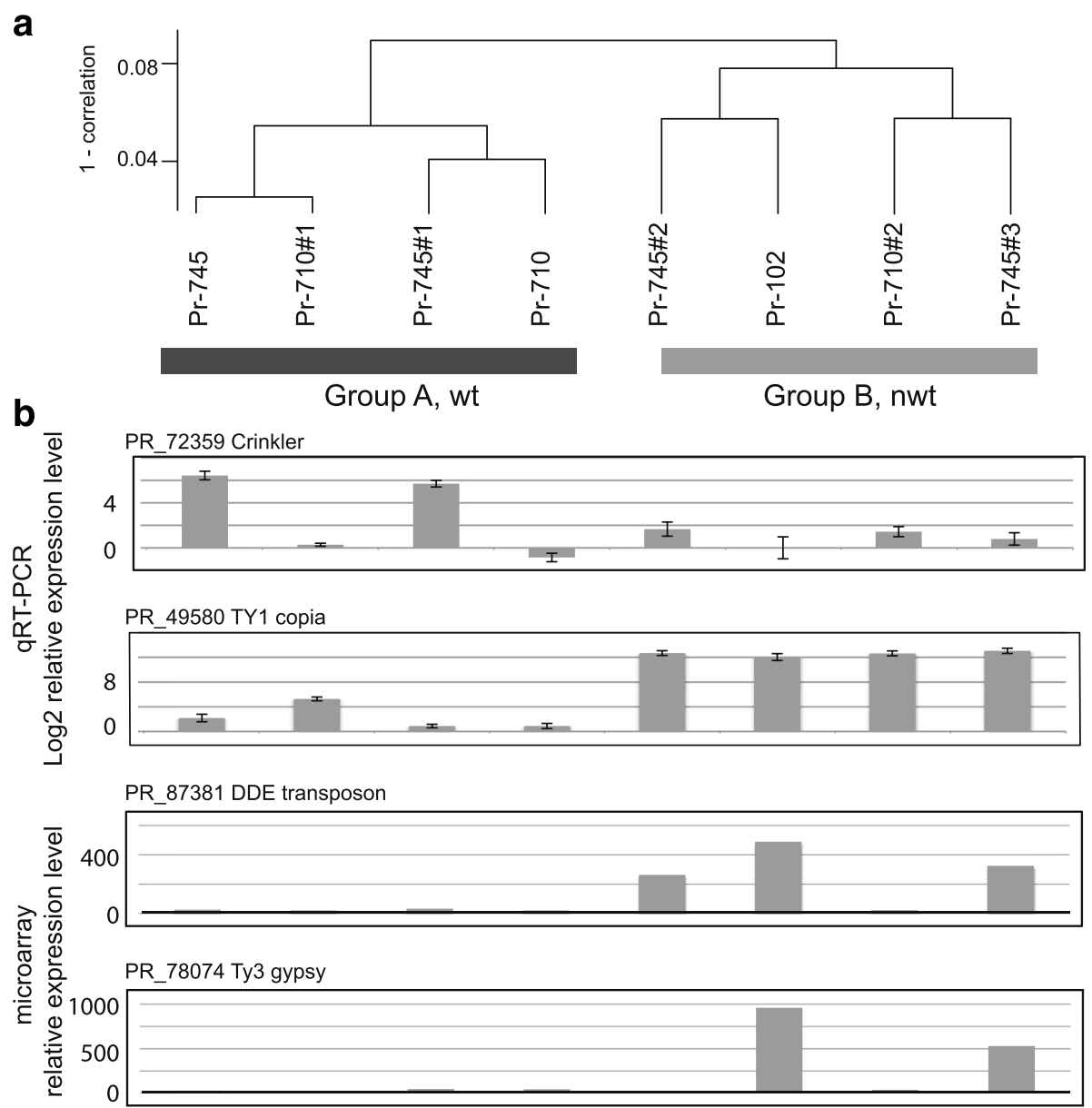

Fig. 2 Transcriptome analyses support host-induced phenotypic diversification. a Eight cDNA samples from Petri plate cultures were clustered based on their global expression patterns of 14,339 transcripts. Group A consists of the two California bay isolates used as inocula and re-isolates from canyon live oak, all having wt colony phenotype. Isolates in group B are either from naturally infected coast live oak or from artificially-inoculated canyon live oak, and all have nwt colony phenotype. $\mathbf{b}$ Examples of mRNA profiles of $P$. ramorum genes differentially expressed between group $A$ and group B. The order of isolates is same as that in $\mathbf{a}$. A gene model number and its annotation are shown for each profile. Gene expression of PR_72359 and PR_49580 were estimated by qRT-PCR, and log2 fold changes $(-\Delta \Delta C T)$ are shown. PR_76099 was used as endogenous control gene, and expression levels were standardized to the genome sequence strain Pr-102. For PR_49580, because the reference PR-102 had a high expression level, its expression was offset by 12 for the presentation purpose. Error bars represent SD in technical replicates. For PR_87381 and PR_78074, bars represent estimates of the relative expression levels according to microarray mRNA profiling

copy number, since these have been reported in association with phenotypic alterations after exposure to antifungal chemicals $[6,7,9,27]$. A read-depth based method called BIC-seq [28] detected variations in chromosomal copy number (CCNV) among NA1 P. ramorum isolates. Remarkably, CCNVs appeared to be colony phenotype dependent. While 17 out of the 19 wt NA1 isolates displayed 0-26 regions with CCNVs (sizes between 100 and $31,800 \mathrm{bp}$ ), all of the seven isolates with $n w t$ colony phenotype, including four oak isolates and three reisolates from oak, produced 171-903 regions with CCNVs (sizes between 100 and 644,200 bp) (the number of CCNV regions in $n w t$ is significantly different from that in $w t$, Fisher's exact test, $p=5.5 \times 10^{-5}$; the size distributions of
$\mathrm{CCNV}$ regions in $w t$ and $n w t$ are also significantly different, Mann-Whitney U test, $p=5.5 \times 10^{-12}$ ) (Table 3).

The majority ( $84 \%$ ) of CCNVs found among the seventeen $w t$ isolates clustered in one of 20 genomic locations, and among these 20 locations, 12 locations were at the vicinity of TEs. Apart from these hypervariable short segments displaying CCNVs, no major chromosomal alterations were detected in the $w t$ isolates, which resulted in a largely linear red line across the concatenated scaffolds when $w t$ isolates were compared (Fig. 4a, upper graph). Additionally, average heterozygous allele ratios, using $10 \mathrm{~KB}$ long non-overlapping sliding window, were close to one (Fig. 4a, lower graph). These observations indicate that the seventeen $w t$ isolates have a balanced set of 
a $\operatorname{Pr}-1556$ (wt, bay)

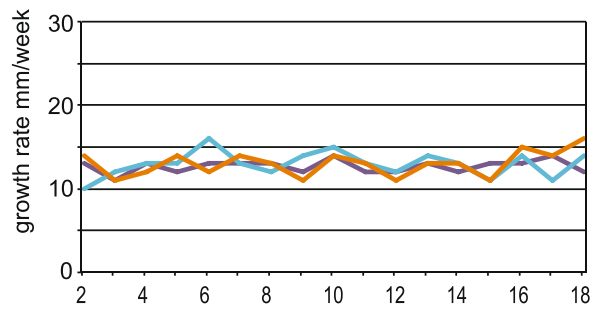

C $\operatorname{Pr}-1556 \# 7 \& \operatorname{Pr}-1556 \# 24(w t$, bay $\rightarrow$ oak $)$

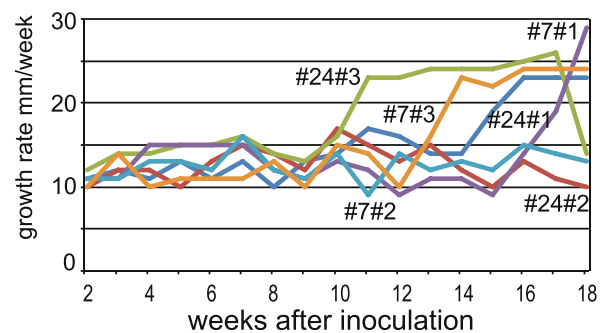

b $\operatorname{Pr}-1557$ (wt, bay)

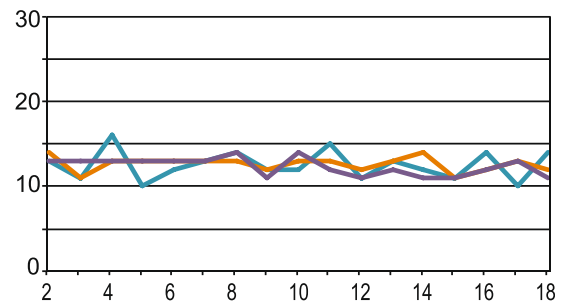

d Pr-1557\#2 \& Pr-1557\#6 (wt, bay $\rightarrow$ oak)

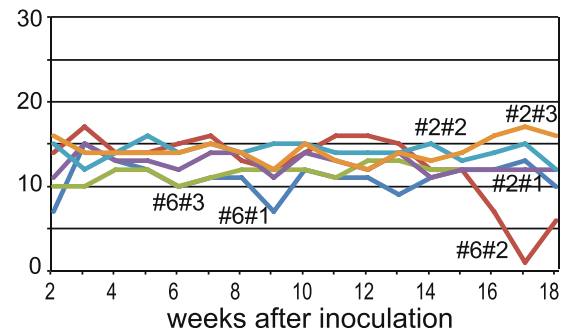

Fig. 3 Wt re-isolates from oak became differentiated from California bay isolates on race tubes. Growth rates of triplicates of California bay isolates a Pr-1556 and $\mathbf{b}$ Pr-1557 were relatively constant for 18 weeks. Growth rates of triplicates of two re-isolates derived from each of $\mathbf{c}$ Pr-1556 and d $\operatorname{Pr}-1557$ were also relatively constant in the first eight weeks (growth rates of the bay isolates and re-isolates are not significantly different between the 2nd and 9th weeks, one-way ANOVA $p=1$ ). However, fluctuation in growth rates became apparent after ten weeks in the race tube (between 10 and 18th weeks, growth rates of bay isolates and re-isolates were significantly different, one-way ANOVA $p=3.5 \times 10^{-3}$ )

chromosomes. This group of isolates was thus classified as the "normal euploid group" (Fig. 4a and Table 3). In contrast, all seven $n w t$ isolates had extensive CCNVs. For instance, when genomes of Pr-745 ( $w t$, bay) and one of its re-isolates, Pr-745\#3 ( $n w t$, bay $\rightarrow$ oak) were compared, a 1.5 -fold increase in chromosomal content was detected for several scaffolds in Pr-745\#3 (Fig. 4b, upper graph). Additionally, average read depths for one of the heterozygous alleles located on duplicated scaffolds were twice those of alternative alleles (Fig. 4b, lower graph). Note that these two independent analyses detected chromosomal alterations at the same locations and that the boundaries of the altered regions coincided completely with those of scaffolds, indicating the precision of the analyses. These observations indicate de-novo copy number change from two to three in the oak re-isolate. The sum of the duplicated

Table 2 Colony phenotypes after retrieval from race tubes

\begin{tabular}{llll}
\hline isolate & replica \#1 & replica \#2 & replica \#3 \\
\hline Pr-1556 (wt, bay) & $w t / w t$ & $w t / w t$ & $w t / w t$ \\
Pr-1557 (wt, bay) & $w t / w t$ & $w t / w t$ & $w t / w t$ \\
ND886 (wt, camellia) & $w t / w t$ & $w t / w t$ & $w t / w t$ \\
Pr-1556\#7 (wt, bay- > oak) & $w t / w t$ & $w t / n w t$ & $w t / n w t$ \\
Pr-1556\#24 (wt, bay- > oak) & senes./senes. & senes./senes. & $n w t / n w t$ \\
Pr-1557\#2 (wt, bay-> oak) & $w t / w t$ & $w t / w t$ & $w t / w t$ \\
Pr-1557\#6 (wt, bay-> oak) & senes./senes. & $n w t /$ senes. & senes./senes.
\end{tabular}

For each race tube replicate, two pieces of mycelial plugs were retrieved and colony phenotypes; wt, nwt or early senescence (senes.), were scored scaffolds for Pr-745\#3 corresponds to nine \% of the total genome.

The current assembly of $P$. ramorum is comprised of 2,576 scaffolds [29] and genetic and physical linkages among the scaffolds are currently unknown. Hence, the duplicated scaffolds seen along the concatenated scaffolds are most probably located on the same chromosome. Given that Phytophthora species usually have five to 12 major chromosomes [30-32] and $P$. ramorum is believed to be $n=10-12$ (D. Beattie and C.M. Brasier, unpublished cytological study), we estimate the duplicated regions correspond to trisomy in one or two whole chromosomes.

Two isolates from naturally infected oak, $\operatorname{Pr}-16$ (nwt, oak) and Pr-102 (nwt, oak), were also found to be trisomic but with a different set of scaffolds (Additional file 3). This group is categorized as " $3 \mathrm{x} C \mathrm{CNV}$ ". In addition, four $n w t$ isolates with intermediate values of chromosome copy number (e.g. Fig. 4e and Additional file 3D,E), indicative of mixtures of nuclei with heterogeneous CCNVs [33], were identified. This group is categorized as "CCNV heterokaryon".

In three oak isolates, large stretches of genomic regions with loss of heterozygosity (LOH) in SNP loci were identified. A $w t$ isolate (Pr-140.9, Fig. 4c) was found to have a 0.5 -fold decrease in the chromosomal content at the $\mathrm{LOH}$ regions. These $\mathrm{LOH}$ regions correspond to monosomy, and thus the isolate $\operatorname{Pr}-140.9$ was classified as "1x CCNV". On the other hand, in the two nwt isolates, MK516a 
Table 3 Summary of SNP and CCNV analyses

\begin{tabular}{|c|c|c|c|c|c|}
\hline Isolate group & CCNV category ${ }^{a}$ & Isolate & Colony phenotype & Reference isolate & $\begin{array}{l}\text { \# CCNV regions } \\
\text { (mean size bp) }\end{array}$ \\
\hline \multirow[t]{26}{*}{ NA1 } & Normal Euploid & MK649b (wt, bay) & $w t$ & used as ref. & $\mathrm{n} / \mathrm{a}$ \\
\hline & Normal Euploid & Pr-1556 (wt, bay) & $w t$ & used as ref. & $\mathrm{n} / \mathrm{a}$ \\
\hline & Normal Euploid & Pr-710 (wt, bay) & $w t$ & used as ref. & $\mathrm{n} / \mathrm{a}$ \\
\hline & Normal Euploid & Pr-745 (wt, bay) & $w t$ & used as ref. & $\mathrm{n} / \mathrm{a}$ \\
\hline & Normal Euploid & $\operatorname{Pr}-745 \# 1$ (wt, bay-> oak) & $w t$ & Pr-710 & $0(0)$ \\
\hline & Normal Euploid & MK548 (wt, bay) & $w t$ & MK649b & $4(2,625)$ \\
\hline & Normal Euploid & MK79j (wt, bay) & $w t$ & Pr-710 & $4(4,350)$ \\
\hline & Normal Euploid & $\begin{array}{l}\text { Pr- } 1556 \# 2 \\
\text { (wt, bay-> race tube) }\end{array}$ & $w t$ & Pr-710 & $6(2,932)$ \\
\hline & Normal Euploid & MK106 (wt, oak) & $w t$ & MK649b & $8(2,211)$ \\
\hline & Normal Euploid & Pr-710\#1 (wt, bay-> oak) & $w t$ & Pr-710 & $9(3,580)$ \\
\hline & Normal Euploid & MK649a (wt, bay) & $w t$ & Pr-710 & $10(3,732)$ \\
\hline & Normal Euploid & $\begin{array}{l}\text { ND886_UC\#1 } \\
\text { (wt, camellia- > bay) }\end{array}$ & $w t$ & Pr-1556 & $10(2,360)$ \\
\hline & Normal Euploid & MK516d (wt, oak) & $w t$ & Pr-710 & $11(2,285)$ \\
\hline & Normal Euploid & $\begin{array}{l}\text { ND886_QA\#7 } \\
\text { (wt, camellia- > oak) }\end{array}$ & $w t$ & MK649b & $11(3,045)$ \\
\hline & Normal Euploid & Pr-1556\#7 (wt, bay-> oak) & $w t$ & MK649b & $12(1,350)$ \\
\hline & Normal Euploid & MK558 (wt, oak) & $w t$ & MK649b & $26(1,050)$ \\
\hline & Normal Euploid & $\begin{array}{l}\text { ND886_QA\#9 } \\
\text { (wt, camellia- > oak) }\end{array}$ & $w t$ & Pr-1556 & $20(5,450)$ \\
\hline & $2 x \mathrm{cnLOH}$ & MK516a (nwt, oak) & $n w t$ & Pr-1556 & $287(3,876)$ \\
\hline & 1x CCNV & Pr-140.9 (wt, oak) & $w t$ & Pr-1556 & $218(8,598)$ \\
\hline & CCNV heterokaryon & Pr-745\#4 (nwt, bay-> oak) & $n w t$ & Pr-1556 & $171(15,536)$ \\
\hline & CCNV heterokaryon & Pr-140.7 (nwt, oak) & $n w t$ & Pr-1556 & $256(11,375)$ \\
\hline & CCNV heterokaryon & $\begin{array}{l}\operatorname{Pr}-1556 \# 7 \# 1 \\
\text { (nwt, bay- > oak- > race tube) }\end{array}$ & nwt & Pr-1556 & $271(41,465)$ \\
\hline & $3 \times$ CCNV & Pr-102_UC\#4 (wt, oak-> bay) & $w t$ & Pr-1556 & $114(27,238)$ \\
\hline & $3 \times$ CCNV & Pr-102 (nwt, oak) & $n w t$ & Pr-745 & $215(14,358)$ \\
\hline & $3 \times$ CCNV & Pr-745\#3 (nwt, bay-> oak) & $n w t$ & Pr-745 & $339(17,271)$ \\
\hline & $3 x \mathrm{CCNV}+2 x \mathrm{cnLOH}$ & Pr-16 (nwt, oak) & $n w t$ & Pr-745 & $903(5,924)$ \\
\hline \multirow[t]{4}{*}{ CCNV generation ${ }^{b}$} & Normal Euploid & $\operatorname{Pr}-1556$ (wt, bay) & $w t$ & used as ref. & $\mathrm{n} / \mathrm{a}$ \\
\hline & Normal Euploid & Pr-1556\#2 ( $w t$, bay- > race tube) & wt & Pr-710 & $6(2,932)$ \\
\hline & Normal Euploid & Pr-1556\#7 (wt, bay- > oak) & $w t$ & MK649b & $12(1,350)$ \\
\hline & CCNV heterokaryon & $\begin{array}{l}\text { Pr-1556\#7\#1 } \\
\text { (nwt, bay- > oak- > race tube) }\end{array}$ & nwt & Pr-1556 & $271(41,465)$ \\
\hline \multirow[t]{3}{*}{$\mathrm{EU} 1^{\mathrm{c}}$} & CCNV heterokaryon & $\begin{array}{l}\text { P2363 (wt, C. lawsoniana), } \\
\text { middle of the lesion }\end{array}$ & $w t$ & Pr-1556 & $2,060(5,105)$ \\
\hline & CCNV heterokaryon & $\begin{array}{l}\text { P2346 (nwt, C. lawsoniana), } \\
\text { bottom of the lesion }\end{array}$ & nwt & P2363 & $473(21,500)$ \\
\hline & CCNV heterokaryon & $\begin{array}{l}\text { P2386 (nwt, C. lawsoniana), } \\
\text { top of the lesion }\end{array}$ & $n w t$ & P2363 & $275(6,546)$ \\
\hline
\end{tabular}

${ }^{a}$ According to CCNV and allele ratio analyses, isolates were categorized into five groups. Details are in the main text

${ }^{\mathrm{b}} \mathrm{NA1}$ clonal isolates subjected to a series of passage experiments were consolidated to highlight the generation of CCNVs. These isolates are also listed under NA1 isolates

${ }^{\mathrm{C}}$ The three EU1 isolates were obtained from the middle, bottom and top of a ca. $4 \mathrm{~m}$ long lesion on Chamaecyparis lawsoniana 


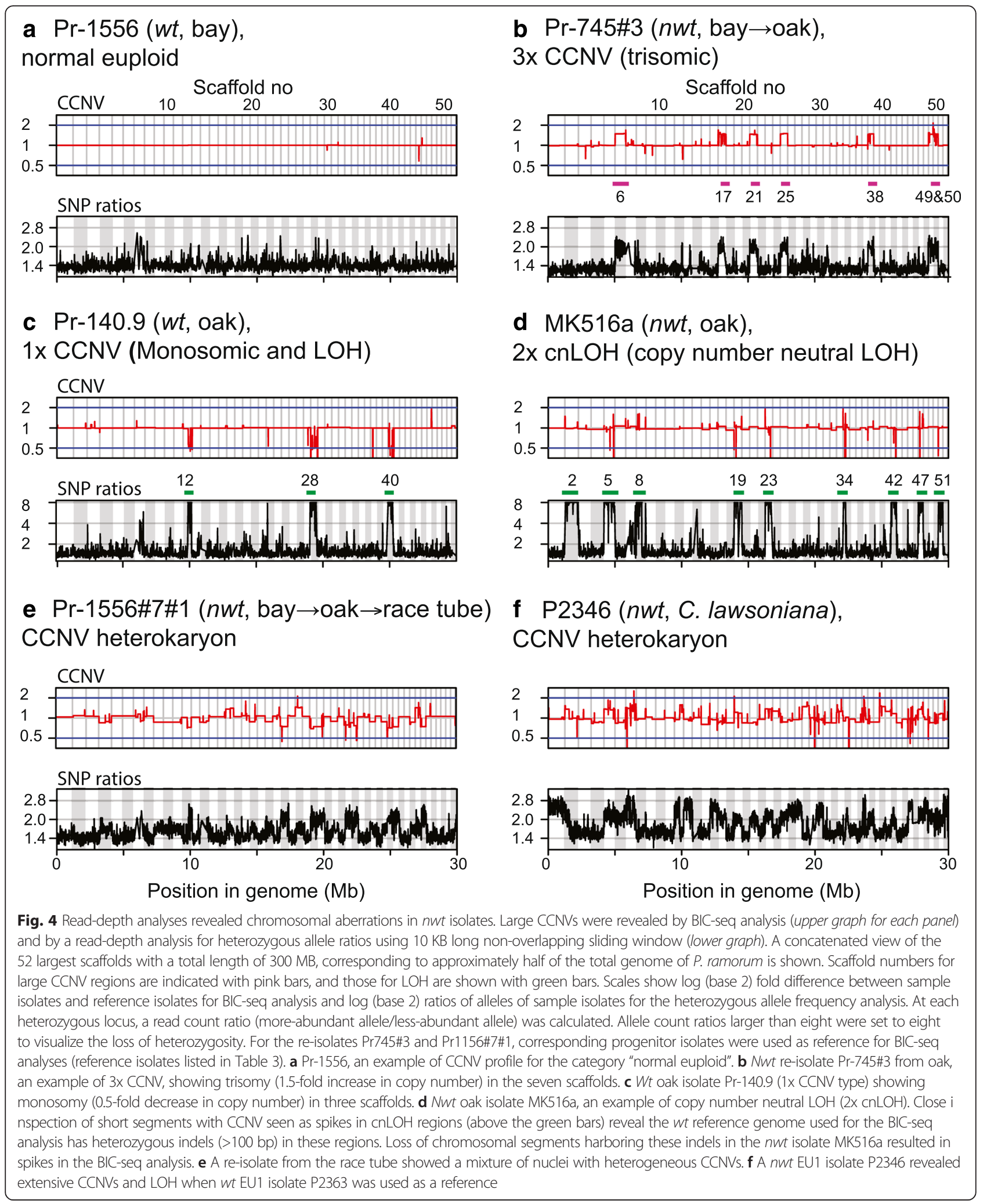

(Fig. 4d) and Pr16 (Additional file 3B), chromosomal copy number changes along the stretches of the $\mathrm{LOH}$ regions were not detected. These $\mathrm{LOH}$ regions correspond to a chromosomal aberration known as uniparental disomy or copy-neutral loss of heterozygosity $(\mathrm{cnLOH})$; these isolates were categorized as " $2 \mathrm{x} \mathrm{cnLOH}$ ". 
A cross-examination of CCNV and SNP datasets revealed a total of four chromosomal breakpoints identified as cnLOH transitions in scaffolds $12,34,37$, and 44 . A disomy to partial monosomy transition was also observed in scaffold 12, and a disomy to partial trisomy transition was observed in scaffold 34. All four breakpoints were found in close vicinity to TEs (Fig. 5, Additional files 4, 5, 6 and 7 for details). Note that except for $\operatorname{Pr}-16$, which was categorized as $3 \mathrm{x} C \mathrm{CNV}$ as well as $2 \mathrm{x} \mathrm{cnLOH}$ (Table 3 and Additional file 3 ) and had four breaks identified in its genome, the other three isolates, Pr-140.9, Pr-102, and MK516a had only one break identified per isolate. Transcriptome analysis did not detect transcripts of TEs (scaffolds 12, 34, and 37) nor differential gene activity of TEs between euploid and aneuploid isolates (scaffold 44) at the breakpoints (Additional file 8), implying that activity of TEs and the formation of chromosomal aberrations is a transient phenomenon.

In summary, $n w t$ isolates have on average a greater number of larger CCNVs than wt isolates do, demonstrating the association of $n w t$ and CCNVs. Also, involvement of TEs in the generation of CCNVs was implicated.

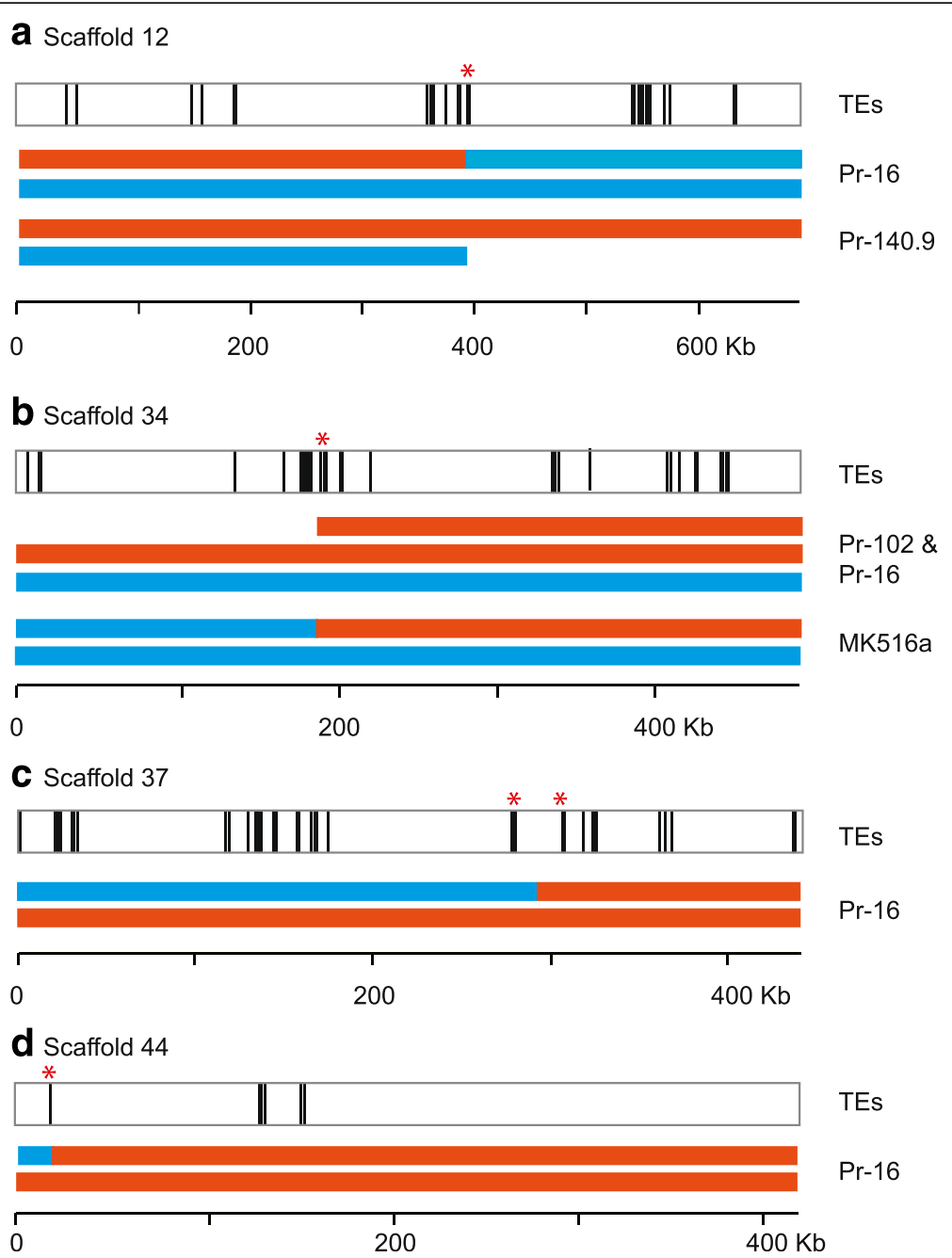

Fig. 5 Chromosomal breakpoints were associated with transposable elements. Of the nine NA1 isolates carrying chromosomal aberrations, a total of seven independent chromosomal breakpoints were identified at four chromosomal locations (see Additional files 4, 5, 6 and 7 for details). Black vertical lines represent transposable elements visualized by Integrative Genomics Viewer [81]. Cyan and orange bars represent segments of homologous chromosomes. a In scaffold 12, chromosomal breakpoints resulted in a partial monosomy in Pr-140.9 and a cnLOH in Pr-16. Two LINE retrotransposons were located at the breakpoint (red asterisk). b In scaffold 34, the chromosomal breakpoints for the partial trisomy (Pr-102 and Pr-16) and cnLOH (MK516a) occurred at the same genomic location. Four gypsy retrotransposons were found at the breakpoint (red asterisk). c Another breakpoint for $\mathrm{cnLOH}$ in Pr-16 was found in scaffold 37. Two gypsy retrotransposons flank the breakpoint (red asterisks). d The third breakpoint for $\mathrm{cnLOH}$ in Pr-16 was located in scaffold 44. A MuDR DNA transposon was located at the breakpoint (red asterisk). Additional files. 4, 5, 6 and 7 show close up of breakpoints 


\section{CCNVs in P. ramorum EU1 lineage exposed to Lawson cypress}

In Europe, two genetically distinct clonal lineages of $P$. ramorum occur, EU1 and EU2 [14, 17]. EU1 isolates, mainly from Rhododendron or Viburnum spp. and from European Beech (Fagus sylvatica), have shown a remarkably high level of stability compared to isolates of the NA1 lineage, and normally exclusively exhibit the $w t$ colony morphology [19]. Furthermore >200 EU1 isolates from destructive unprecedented outbreaks on plantation larch (Larix spp.) in the UK starting in 2009 [11] have also been described as $w t$. However, in 2010, twenty-five EU1 isolates obtained from the phloem of a single four meter long lesion on a mature Lawson cypress (Chamaecyparis lawsoniana) in the UK [34], displayed diverse colony types. It is estimated that from the time of the original infection the pathogen was probably active in this lesion for at least three seasons. Five isolates from the middle of the lesion all had the $w t$ phenotype and remained $w t$ in re-subculturing (Additional file 9D,E,F). Seven from the top front of the lesion were initially a mixture of $w t$ and $n w t$ phenotypes, but all became $n w t$ on re-subculturing (Additional file 9A,B,C). Many isolation attempts from the bottom lesion front failed, and some isolates senesced before they could be subcultured, but all of the thirteen successful isolates were and remained nwt (Additional file 9G,H,I).

Three representative isolates, one reference $w t$ from the middle of the lesion and two nwt from the top and bottom lesion fronts (Table 3) were subjected to CCNV analysis. Large chromosomal regions with CCNVs and $\mathrm{LOH}$ were identified in the EU1 nwt isolates in comparison to both the EU1 wt (Table 3, Fig. 4f and Additional file 3F) and the NA1 $w t$ reference isolates (Additional file 10). Intermediate values of chromosomal copy number and the increase in SNP allele ratios at heterozygous loci indicate the three isolates (one $w t$ and two $n w t$ ) were CCNV heterokaryons.

\section{CCNVs in relation to the growth acceleration phenotype (GAP)}

To obtain information on the development of CCNVs, GAP, and $n w t$ phenotype, a CCNV analysis was conducted on the isolates which had been subjected to a series of passage experiments (CCNV generation in Table 3). No major CCNVs or noticeable changes in SNP allele ratios were seen in the inoculum isolate Pr-1556 (wt, bay), re-isolate from oak Pr-1556\#7 (wt, bay $\rightarrow$ oak), or the inoculum isolate passed through the race tube, Pr-1556\#2 (wt, bay $\rightarrow$ race tube) (all similar to Fig. 4a). In contrast to the genome of Pr-1556 (wt, bay), which was stable over 18 weeks of growth in the race tube (Pr-1556\#2), Pr-1556\#7\#1 (nwt, bay $\rightarrow$ oak $\rightarrow$ race tube) was found to be a CCNV heterokaryon (Fig. 4e), supporting the notion that oak but not California bay destabilizes the genome of P. ramorum.

\section{Genes in duplicated chromosomal regions are over- expressed}

Differential expression of genes located on the duplicated regions is expected and may be responsible for the phenotypic changes in oak isolates. Global mRNA profiles of trisomic isolates Pr-102 ( $n w t$, oak) and Pr-745\#3 (nwt, bay $\rightarrow$ oak) were compared with those of the four $w t$ normal euploid isolates (Fig. 2). As a result, 1,400 and 715 differentially expressed genes in Pr-102 ( $n w t$, oak) and Pr745\#3 (nwt, bay $\rightarrow$ oak), respectively, were identified (Additional file 8). Microarray analysis detected expression of 217 and 913 genes located in duplicated regions in the first $30 \mathrm{Mb}$ of the concatenated scaffolds in Pr-102 and Pr-745\#3, respectively. Genes on the duplicated regions were found more likely to be up-regulated $\left(p=3.2 \times 10^{-5}\right.$ for Pr-102 and $2.0 \times 10^{-5}$ for Pr-745\#3) but not downregulated in relation to the genome average. Such overexpression of duplicated genes may be responsible for the observed phenotypic changes.

\section{Discussion}

Epidemiological and experimental studies support the hypothesis that oak is a dead-end for Phytophthora ramorum and that propagules produced on infectious hosts such as California bay initiate infection on oak [22, 23]. The fact that unusual non wild-type phenotypic variation $(n w t)$ has been observed in oak isolates and not in California bay populations of P. ramorum [21] together with the evidence that California bay populations provide the inoculum source for the oak populations suggests that: 1)- the genomic changes involved in $n w t$ occur once the pathogen colonizes oak and that 2)colonization of oak does not exert a similar selection pressure on the $P$. ramorum genome as colonization of California bay.

Since the oak- $n w t$ variation apparently occurs in the absence of any genetic differentiation in the P. ramorum population [21], the concept of host-induced phenotypic diversification (HIPD) was formulated. The main objective of the present study was to demonstrate HIPD experimentally and gain insight into the underlying genetic mechanisms. When wild type (wt) isolates from California bay were artificially inoculated on both oak and California bay, HIPD was observed only when the pathogen was re-isolated from oak. In these tests, colony morphologies and mRNA profiles of wild type $(w t)$ isolates converted to non-wild type $(n w t)$ through artificial oak inoculation matched the colony morphologies and the mRNA profiles of $n w t$ isolates obtained from naturally infected oak. This is further evidence that $n w t$ isolates are not a permanent subpopulation specialized in oak but they arise de novo inside oak from the general population. The $n w t$ colony phenotype was not always observable among re-isolates immediately after retrieval 
from inoculated hosts, but did develop in re-isolates from oak during subsequent in vitro colony growth.

In the sequence analyses, $n w t$ colony morphology was found to be strongly correlated with a range of chromosomal aberrations including aneuploidy and chromosomal number neutral loss of heterozygosity ( $\mathrm{cnLOH})$. A similar association of $n w t$ phenotype and chromosomal aberrations was observed in the EU1 isolates from Lawson cypress. Induction of aneuploidy has been reported in several fungal pathogens in response to antifungal chemical treatments $[6,9]$. Also, some viral, bacterial, and fungal pathogens are known to modify host cell ploidy (e.g. [35-37]). In oomycetous pathogens, field isolates with aneuploidy have been identified in diverse species [38-41] and meiotic generation of aneuploids has also been reported [32, 42, 43]. Likewise, mitotic $\mathrm{cnLOH}$ has been detected in field isolates and intercross progeny and shown a strong association with changes in pathogenicity [44]. Our observation of a presumed mitotic generation of aneuploidy and $\mathrm{cnLOH}$ in oak and Lawson cypress is to our knowledge the first report of aneuploidy in a defined host-pathogen interaction in nature.

The location of chromosomal breakpoints associated with the genome aberrations may provide clues to the mechanisms underlying the induced aneuploidy and $\mathrm{LOH}$. Of the total of four identified breakpoints in NA1, two (scaffolds 12 and 34 in Fig. 5) were shared among multiple isolates displaying $\mathrm{cnLOH}$ and aneuploidy. Given that oak is a dead-end host for $P$. ramorum, with no oak-to-oak infection, the shared chromosome breakpoints must be of independent origin. Evidence from other organisms indicates that formation of breakpoints is non-random and that common genetic mechanisms occur. These include breakage of chromosomes at common fragile sites under replication stress, followed by repair of the double-strand breaks via homologous recombination, resulting in partial aneuploids and cnLOH [45-47]. All four breakpoints in P. ramorum NA1 were located at or near TEs. This is in agreement with the observation that TEs were located at the breakpoints of segmental aneuploids in Saccharomyces cerevisiae [48]. Association of TEs and chromosomal breakage during mitotic divisions is also well established $[49,50]$. For example, Ty retrotransposons have also been found near double-stranded DNA breaks in mitotically dividing cells in S. cerevisiae [51]. This is consistent with our finding of retrotransposons near the breakpoints in $P$. ramorum scaffolds 12, 34, and 37.

Three NA1 and three EU1 isolates were shown to be a mixture of euploid and aneuploid nuclei. The spatial distribution of the nuclear mixture could be structured or homogeneous (equally distributed throughout the mycelia). For example, if structured, some hyphae would have exclusively euploid nuclei, and other hyphae exclusively aneuploidy nuclei. If distribution is homogenous, all hyphae would have both nuclear types (i.e. be heterokaryotic). Because (1) oomycete cells are multinucleate and heterogeneous nuclei can coexist within a single cell [52, 53], and because (2) euploid and aneuploid hyphae can have a significant difference in growth rates $[54,55]$, the cultures with mixed nuclei are most likely to be heterokaryotic.

It is noteworthy that the three EU1 isolates from a single lesion on Lawson cypress showed different ratios of euploid to aneuploid nuclei (Additional file 10). The $w t$ isolate P2363 showed the least deviation from one in the ratios of heterozygous SNP alleles when compared to $n w t$ isolates P2346 and P2386. Therefore, P2363 hyphae contained the least number of aneuploid nuclei. Hence, it could be that a higher ratio of aneuploid to euploid nuclei in the hyphae results in the $n w t$ phenotype. Indeed, such an increase in nuclear ratio could also explain the phenomenon of latent development of $n w t$ colony morphology in $w t$ isolates during growth in vitro, which has been observed in both the oak and Lawson cypress isolates.

Some recent evidence suggests that the generation of aneuploids and $\mathrm{LOH}$ can result in episodic selection (rapid adaptation to environmental shifts) [9, 33]. For example, in the human pathogens Candida albicans and Cryptococcus neoformans, antifungal drug resistance is conferred by duplication of chromosomes harboring genes for drug targets (reviewed in [9]). A rapid generation of $\mathrm{LOH}$ in the presence of an antifungal drug has also been observed for S. cerevisiae [56]. It is posited that aneuploidy generates changes in gene dosage and, therefore, creates a phenotypic variation on which selection can act [57]. $\mathrm{LOH}$ can remove dominant alleles so that potentially beneficial recessive alleles can contribute to an organism's phenotype. LOH can, therefore, allow beneficial recessive alleles to escape Haldane's sieve [56]. Present evidence indicates that in P. ramorum nwt individuals are ecologically less fit than $w t$ individuals in that they are less pathogenic and slower growing and prone to senescence in culture [19-21]. There could, however, be circumstances where phenotypes driven by host-induced aneuploidy confer survival advantages to pathogens. Thus, we cannot altogether discount the possibility that the resulting phenotypic diversification may allow an introduced pathogen such as $P$. ramorum to adapt to a novel host or to other episodic selection conditions $[2,58]$.

Although induced chromosomal aberration as a result of host defense is currently unknown to science, the observed $n w t$ phenotype may be due to damage inflicted directly by the host's defense mechanisms, such as induced or constitutive metabolites, resulting in induced chromosomal aberration (see below). Thus the colony instability, slower growth rates and lower aggressiveness of the $n w t$ phenotype can be viewed as degenerate and at a fitness disadvantage 
compared to the $w t$ form. Indeed, individual oak trees infected with $P$. ramorum do not always die suddenly. Some live for many years and in others the infection may die out [59]. Such oak survival may be associated with the conversion of $P$. ramorum to slow growing $n w t$, allowing the host to contain it, or the pathogen may become senescent and therefore effectively eradicated, as appears to have occurred at the perimeter of the large lesion on Lawson cypress.

The host factors that trigger HIPD remain unknown. Chronic exposure to specific chemicals in oak and Lawson cypress bark may make nuclei prone to chromosomal abnormalities, whereas exposure to the chemical environment of other hosts such as California bay or Rhododendron may not. The phloem of coast live oak contains a mixture of chemicals including phenolics, some of which are associated with field resistance to $P$. ramorum [60, 61]. Likewise, bark and wood of Lawson cypress also contains a wide range of secondary metabolites including polyphenols and oils such as limonene that exhibit antifungal activity [62]. Additionally, Lawson cypress oil is reported to contain about $2 \%$ camphor [63]. Camphor has been used to induce polyploidy in the true fungi and oomycetes including Phytophthora [64]. The 3-4 years that $P$. ramorum spent in the bark of the Lawson cypress canker would have provided ample time for bark compounds to induce chromosomal abnormalities. The possible role of camphor, and other bark constituents of Lawson cypress and oak in inducing $n w t$ phenotype in $P$. ramorum could be tested experimentally in further race tube tests.

We have shown that high-throughput sequencing methods for CCNV and $\mathrm{LOH}$ detection are fast, reliable, and produce high-resolution data. They should, therefore, be valuable additional tools for understanding the genetics of evolutionary processes not just in Phytophthora, but in other organisms as well. The quality of genome assembly is vital to the CCNV and $\mathrm{LOH}$ analyses. In future we suggest the resolution and sensitivity of studies on structural variations of chromosomes may be significantly improved by applying long-read sequencing and genome assembly technologies to the assembly of full-length chromosomes $[65,66]$.

\section{Conclusions}

The Sudden Oak Death pathogen Phytophthora ramorum is exclusively clonal, yet exhibits extensive phenotypic differences when obtained from oak. When P. ramorum isolates from the foliar host California bay were inoculated and re-isolated from canyon live oak, a large number of re-isolates displayed morphological phenotypes and mRNA expression profiles only seen in cultures from naturally infected oak. Major genomic alterations in oak isolates including partial aneuploidy and copy-neutral loss of heterozygosity were found to be associated with the observed phenotypic diversification. Comparable phenotypic changes and associated genome alterations were also found in isolates from Lawson cypress in the UK. Chromosomal breakpoints were found to be located at or near transposons, linking transposon de-repression caused by the chemical environment of oak to structural genomic changes.

\section{Methods}

In this research, $P$. ramorum isolates derived from California bay were 1) inoculated into oak and California bay, and the pathogen was re-isolated and changes in colony phenotypes were recorded. Microarray mRNA profiling and illumina DNA-seq were used to address processes underlying the phenotypic conversion. All permits to work with P. ramorum in the lab and the field in California have been secured from the California Department of Agriculture (Permit No. 2201). Collecting permits have also been obtained for all sites where field plots have been established. These include California State Parks (blanket permit for all state parks), National Park Service (Redwood National Park and associated North Coast State Parks, Pt. Reyes National Seashore), Marin Municipal Water District, Monterey Regional Parks District, East Bay Regional Parks, Big Sur Land Trust, and Midpeninsula Regional Open Space District.

\section{Isolates and culture conditions}

A total of 41 Californian and three British P. ramorum isolates were examined in this study (Additional file 2 for details). Cultures were maintained on small plugs of $6.6 \%$ clarified V8 Juice with $1.5 \%$ agar (1/3 x CV8A) [67] submerged in water at $14{ }^{\circ} \mathrm{C}$.

\section{Inoculation and re-isolation}

Inoculation experiments on oak were conducted twice. In July 2010, we initiated the first experiment by inoculating 18 canyon live oaks and two Shreve oaks at a site in San Mateo County (details in [26]). Holes five $\mathrm{mm}$ in diameter were made to the cambial zone of mature trees (25 cm average diameter at breast height) with a cork borer and inoculation was made with a five $\mathrm{mm}$ diameter agar plug cut from the margin of a 7-day old culture growing on $1 / 3$ V8A (6.6 \% non-clarified V8 with $1.5 \%$ agar), following procedures previously used for coast live oak [10]. Each tree was inoculated with two different local $P$. ramorum isolates, $\operatorname{Pr}-710$ and $\operatorname{Pr}-745$, and a control mock inoculation (sterile agar only). Pr-710 was originally derived from California bay, whereas Pr-745 was derived from rainwater near infected California bay trees. Twenty and 40 weeks after inoculation, cankers that developed under tree bark were exposed and small pieces of phloem tissue cut from canker margins were placed onto PARP selective medium [68] for re-isolation 
of $P$. ramorum. The second oak inoculation experiment was initiated in July 2012. Four canyon live oak trees (previously inoculated, but appeared healthy) were selected and two other local P. ramorum isolates, Pr-1556 and Pr-1557, both derived from California bay, were inoculated to locations distant enough to avoid merging into the earlier July 2010 inoculations. Re-isolation was performed 20 weeks after inoculation.

Inoculation experiments on California bay were also conducted twice. In April 2012, 10 leaves of one 18-L potted California bay seedling were wounded with a surgical scalpel. Inoculum plugs five $\mathrm{mm}$ in diameter were taken from an actively growing margin of $P$. ramorum colony of isolate Pr-745 (wt, bay) on 1/3x V8A. Plugs were placed mycelium side up into a screw cap lid from a microcentrifuge tube filled with sterilized $\mathrm{dH}_{2} \mathrm{O}$ and then attached to the underside of the leaves with a pin curl clips. A clear plastic bag filled with $10 \mathrm{ml}$ of sterilized $\mathrm{dH}_{2} \mathrm{O}$ was placed over each inoculated leaf. Bags and clips were removed three days post-inoculation. Plants were kept in $18{ }^{\circ} \mathrm{C}$ growth chamber and re-isolations were made with PARP selective medium 20 weeks post-inoculation. The second California bay inoculation experiment was initiated in January 2013. Fifteen leaves each of six 18-L potted California bay seedlings were inoculated with isolates ND886 ( $w t$, camellia) and Pr-102 (nwt, oak), three seedlings each. Plants were kept outdoors at the National Ornamentals Research Sites at Dominican University of California (NORS-DUC), and re-isolations were made 4, 12 and 25 weeks post-inoculation from three leaves per plant at each time point.

\section{Evaluation of colony morphology}

$P$. ramorum isolates were first grown on $1 / 3 \mathrm{x}$ CV8A at $21{ }^{\circ} \mathrm{C}$ for seven days and then subcultured to $1 \mathrm{x}$ CV8A (20\% clarified V8 Juice with $1.5 \%$ agar) and grown for another seven days. Colony diameters were measured and colony patterns were photo-documented for at least two replicates per isolate. Colonies that had a uniform circular growth pattern were scored as "wild type" (wt). Criteria for $n w t$ morphology are as follows. If (1) the growth rate was slower than $w t$ by at least $25 \%$ of the average linear growth rate of $w t$ or (2) at least $15 \%$ deviation of radius was observed within a $45^{\circ}$ sector in a single colony, these colonies were scored as "non-wild type" (nwt). When nwt colony morphology was observed upon further subculturing, the phenotype of the isolate was described as $n w t$ even though the original isolate did not consistently display nwt colony morphology. When growth arrest was observed, isolates were scored as displaying "early senescence phenotype".

\section{Race tube growth experiment}

A race tube is a $40 \mathrm{~cm}$ long glass tube that is bent up at both ends to hold agar medium (purchased from Fungal
Genetic Stock Center, Kansas City, Missouri USA) [69]. $20 \mathrm{ml}$ of autoclaved 1x CV8A (20 min. $121{ }^{\circ} \mathrm{C}$ ) was poured into the autoclaved race tube, then both ends were capped with plastic lids. After the medium had solidified, a small piece of mycelium was inoculated at one end of the race tube, Parafilm was wrapped around the lids and incubated at $21{ }^{\circ} \mathrm{C}$ under constant cool white fluorescent light at $3.4 \mu \mathrm{mol} \mathrm{m}{ }^{-2} \mathrm{~s}^{-1}$. The mycelial front was marked once a week to measure growth rate. When the mycelium reached the other end of the race tube, which was after 18 to 25 weeks, the isolate was recovered, grown on $1 \mathrm{x}$ CV8A and colony phenotypes were recorded. Owing to the genetic instability of archival oak isolates [21], this experiment could not be repeated for some isolates.

\section{Growth conditions and RNA extraction for microarray analysis}

Growth conditions and RNA extraction [21, 70] were described previously. Mycelia grown on Petri plates (60 mm diameter, catalog no. 351007; Corning Inc.) containing seven $\mathrm{ml}$ of $1 \mathrm{x}$ CV8A overlaid with a polycarbonate membrane filter (catalog no. 28157-927; VWR) for seven days at $21{ }^{\circ} \mathrm{C}$ under constant cool white fluorescent light were subjected to RNA extraction. FastPrep24 automated cell disruptor was used to homogenize tissues followed by the TRIzol RNA extraction (Invitrogen Life Technologies). Up to $100 \mu \mathrm{g}$ of total RNA was further cleaned using the RNeasy mini protocol for RNA cleanup (Qiagen). cDNA synthesis, labeling, hybridization procedure, data acquisition and normalization were carried out for NimbleGen microarray analysis according to the manufacturer's instructions (Roche NimbleGen). Global expression patterns of eight $P$. ramorum isolates were investigated where no biological or technical replicates were included. Results were subsequently validated by qRT-PCR using independently generated RNA samples as described in [21]. Quantile normalization and background correction across arrays were performed using Robust Multi-chip Average (RMA) algorithm [71] implemented in the NimbleScan Version 2.5 software. A MIAMEcompliant microarray dataset [72] has been deposited in NCBI GEO database (accession number GSE62643). Additional file 8 lists normalized mRNA profiling results and functional annotations.

\section{Microarray data analysis}

Two isolates derived from California bay, one from coast live oak and five re-isolates from canyon live oak were subjected to microarray analysis. Microarray design and data analysis can be found in our previous report [21]. An additional 2,506 cDNA sequences, which were not represented in the 15,743 gene models predicted in Phytophthora ramorum v1.1 (http://genome.jgi-psf.org/ 
Phyra1_1/Phyra1_1.home.html), were also included in the array. Normalized intensity data for 18,001 genes across eight arrays were obtained by RMA and genes with average hybridization intensity below 64 were removed from the dataset. The remaining 14,339 genes were used for further analysis. Pearson's correlation coefficient between global mRNA expression patterns was then used to cluster cDNA samples using the hclust function with the single linkage option in the statistical software R 3.1.0.

\section{DNA extraction for Illumina DNA sequencing}

A small mycelial plug was transferred to each Petri plate (6 mm diameter, catalog no. 351007; Corning Inc.) containing seven $\mathrm{ml}$ of $1 \mathrm{x}$ CV8A overlaid with a polycarbonate membrane filter (catalog no. 28157-927; VWR), and grown for seven days at $21{ }^{\circ} \mathrm{C}$ in dark. Each circular mycelial mat was cut in half, and lifted from the polycarbonate membrane surface; each half was transferred to a two ml screwcap microcentrifuge tube (catalog no. 72.694.996 Sarstedt; Fisher Scientific, Santa Clara, CA, USA) and immediately snap-frozen in liquid nitrogen. Each sample weighed approximately $100 \mathrm{mg}$ and was kept at $-80{ }^{\circ} \mathrm{C}$ until ready for processing. Lysing Matrix A (MP Biomedicals) chilled at $-20^{\circ} \mathrm{C}$ was added to each of the frozen samples and chilled in liquid nitrogen. Cells were then disrupted once using a FastPrep-24 automated cell disruptor, set at six meters/s for $40 \mathrm{~s}$, in a CoolPrep adapter filled with crushed dry ice. Cells were chilled in liquid nitrogen and disrupted once more for $40 \mathrm{s.} 1.5 \mathrm{ml}$ of lysis buffer ( $20 \mathrm{mM}$ EDTA, $10 \mathrm{mM}$ Tris-Cl, pH7.9, $0.7 \mathrm{mg} / \mathrm{ml}$ of enzyme mix, $1 \%$ Triton X-100, $500 \mathrm{mM}$ Guanidine- $\mathrm{HCl}$, and $200 \mathrm{mM} \mathrm{NaCl}$ ) was added to the pulverized sample, and genomic DNA was extracted according to the User-Developed Protocol for filamentous fungi using the Qiagen Genomic-tip 20/G [73]. A combination of enzymes developed for digesting cell wall material of Phytophthora infestans was used [74, 75]; 10x concentration of enzyme mix stock solution comprised of $5 \mathrm{mg} / \mathrm{ml}$ Lysing Enzymes from Trichoderma harzianum (Sigma-Aldrich) and $2 \mathrm{mg} / \mathrm{ml}$ cellulose Onozuka R-10 (Research Products International Corp) was prepared and stored at $-20{ }^{\circ} \mathrm{C}$ until use, and an appropriate volume was added to prepare a final $1 \mathrm{x}$ concentration in the lysing buffer. This method yielded up to $10 \mu \mathrm{g}$ of genomic DNA. Paired-end libraries were constructed according to the manufacturer's instructions for TruSeq DNA HT Sample Prep Kit (Illumina, Inc). Conditions and output of Illumina sequencing are in Additional file 11.

\section{DNA-seq data analysis}

A Bayesian adapter trimmer program, Scythe [76] and quality based trimmer, Sickle [77] were used to clean Illumina reads. The processed reads were aligned to the reference genome of $P$. ramorum isolate Pr-102 [29] using Burrow-Wheeler Aligner (BWA) [78] with default parameters. SAMtools was used to process aligned reads [79] and single nucleotide polymorphisms (SNPs) were identified from the aligned reads using Bcftools [80]. Any SNPs whose phred-scaled quality score was 20 or below were filtered out. Chromosomal copy number variation (CCNV) was evaluated by two methods. The first method detects CCNVs from BWA aligned reads using a read-depth algorithm called BIC-seq [28]. To minimize experimental noise, one reference California bay isolate was chosen for each sequencing run and used to estimate CCNVs in the samples processed and run on the Illumina genome sequencer at the same time (Table 3). Because CCNVs between California bay isolates were small, different California bay isolates effectively served as references. The current assembly of the P. ramorum genome is comprised of 2,576 scaffolds. These scaffolds were concatenated in order from largest to smallest and $\mathrm{CCNVs}$ identified. The second method infers CCNV from read-depth ratios of alleles at heterozygous sites. In the Bcftools output, any heterozygous loci with phred quality scores smaller than 30 were filtered out. Also, any loci carrying alleles with strand bias deviating from a 1:1 ratio (chi-square test $p<$ 0.01 ) were filtered out. Any loci with read ratios of heterozygous alleles equal or larger than eight were also excluded. An average ratio of reads of heterozygous alleles in sliding non-overlapping windows of $10 \mathrm{~Kb}$ across each scaffold was then used to infer CCNVs [6]. Loss of heterozygosity $(\mathrm{LOH})$ was also inferred from read-depth ratios of alleles at heterozygous sites. This method is identical to the second $\mathrm{CCNV}$ analysis mentioned above but strand bias was not considered, and any allele ratios equal or larger than eight were set to 8 . Re-sequencing of 37 isolates identified on average a SNP in every $320 \mathrm{bp}$ in the genome of $P$. ramorum. These SNPs and CCNVs were used to locate chromosomal breakpoints manually using the Integrative Genomics Viewer [81]. Genome coordinates of transposable elements, which can be found at Eumicrobedb.org [82], were kindly provided by Dr. Rays Jiang, University of South Florida.

\section{Data availability}

Additional file 8 contains genome information and mRNA profiling results. The accession number for a MIAME-compliant microarray dataset deposited in NCBI GEO database is GSE62643. BAM alignment files for illumina DNA sequence data were deposited in the NCBI Sequence Read Archive under BioProject accession number SRP061242. 


\section{Additional files}

Additional file 1: Nwt colony morphology seen among Petri plate replicates. Nwt is observed in $\mathbf{A}$ ) oak isolate Pr-102 (nwt colonies indicated with asterisks) but has not been observed for $\mathbf{B}$ ) Pr-745 from rainwater collected near infected California bay. Colonies were grown on solid $1 \mathrm{x}$ CV8A medium for 7 days at $21^{\circ} \mathrm{C}$ in dark. Criteria for nwt morphology can be found in Evaluation of colony morphology in Methods. (PDF $18884 \mathrm{~kb}$ )

Additional file 2: Details of $P$. ramorum isolates used in this study. Other names, source, geographical location, year of isolation and contact scientists for isolates are shown. (XLSX $48 \mathrm{~kb})$

Additional file 3: Diverse CCNVs revealed by BIC-seq analysis (upper graph for each panel) and a read-depth analysis for heterozygous allele ratios using $10 \mathrm{~Kb}$ long non-overlapping sliding window (lower graph). A concatenated view of the 52 largest scaffolds with the total length of 300 $\mathrm{MB}$, which corresponding to approximately a half of the total genome of Phytophthora ramorum, are shown. Scaffolds numbers for large CCNV regions are indicated with pink bars, and those for $\mathrm{LOH}$ are shown with green bars. Scales show log (base 2) fold difference between sample isolates and reference isolates for $\mathrm{BIC}$-seg analysis and log (base 2) ratios of alleles of sample isolates for the heterozygous allele ratio analysis. At each heterozygous locus, a read count ratio (more-abundant allele/ less-abundant allele) was calculated. A) Pr-102, the genome sequence isolate is trisomic. B) Oak isolate Pr-16 is trisomic as well as $\mathrm{cnLOH}$. C) Trisomy persists in a re-isolate of Pr-102 from California bay. D) A re-isolate $\operatorname{Pr} 745 \# 4$ and $\mathbf{E}$ ) an oak isolate $\mathrm{Pr}-140.7$ are CCNV heterokaryons. F) nwt EU1 isolate P2386 revealed CCNVs and $\mathrm{LOH}$ when wt EU1 isolate P2363 was used as a reference. (PDF $1014 \mathrm{~kb}$ )

Additional file 4: The chromosomal breakpoint in scaffold 12. From the right most heterozygous SNP and the left most SNP with $\mathrm{LOH}$, the breakpoints for Pr-140.9 (monosomy) and Pr-16 (cnLOH) were inferred to be within the $1.3 \mathrm{~kb}$ red rectangle region (top panel, Integrative Genomic Viewe ver. 2.3.34). BICseq CCNV analysis for Pr-140.9 inferred the breakpoint in the close proximity to the red rectangle (middle panel). Homologous chromosomes are depicted in orange and cyan (lower panel). (PDF 57 kb)

Additional file 5: The chromosomal breakpoint in scaffold 34. From the right end of the $5.0 \mathrm{~kb}$ indel and the left most heterozygous SNP, the breakpoint for MK516a ( $\mathrm{cnLOH})$ is inferred to be somewhere within the $7.5 \mathrm{~kb}$ red rectangle region (top panel, Integrative Genomics Viewer ver. 2.3.34). For Pr-102 (trisomy) and Pr-16 (trisomy), ratios of heterozygous SNP reads are not reliable for inference for the precise transition from disomy to trisomy. BICseq CCNV analysis, however, located the breakpoints for Pr-102 and Pr-16 at positions 191,470 bp and 190,370 bp, respectively (only Pr-16 is shown in the middle panel), which are within the red rectangle range. Homologous chromosomes are depicted in orange and cyan (lower panel). (PDF 63 kb)

Additional file 6: The chromosomal breakpoint in scaffold 37. From the right most heterozygous SNP and the left most SNP with LOH, the breakpoint for $\operatorname{Pr}-16(\mathrm{cnLOH})$ was inferred to be within the $3.0 \mathrm{~kb}$ red rectangle region (top panel, Integrative Genomic Viewer ver. 2.3.34). Note that $\mathrm{Pr}-1556$ is a normal diploid isolate having heterozygous SNP loci on the right of the breakpoint. Homologous chromosomes are depicted in orange and cyan (lower panel). (PDF $51 \mathrm{~kb}$ )

Additional file 7: The chromosomal breakpoint in scaffold 44. From the right most heterozygous SNP and the left most SNP with $\mathrm{LOH}$, the breakpoint for Pr-16 (cnLOH) was inferred to be within the $1.3 \mathrm{~kb}$ red rectangle region (top panel, Integrative Genomic Viewer ver. 2.3.34). Homologous chromosomes are depicted in orange and cyan (lower panel). (PDF 46 kb)

Additional file 8: Genome information and mRNA profiling results. This dataset provides mRNA profiling results and information for each gene such as functional annotation, GO terms, transposon class and expression clusters for 12,450 detected genes by means of $P$. ramorum NimbleGen expression microarray. Each of columns is explained in the attached worksheet "Readme". (XLSX 3418 kb)

Additional file 9: Nwt colony morphology seen among EU1 isolates obtained from a single $4 \mathrm{~m}$ long lesion on a mature Lawson cypress. EU1 isolates $(\mathbf{A}-\mathbf{C})$ are derived from the top, (D-F) are from the middle, and
(G-I) are from the bottom of the lesion. Mnwt and snwt indicate moderate and severe non-wild types, respectively. (PDF 234 kb)

Additional file 10: BIC-seq analysis for three EU1 isolates using an NA1 isolate Pr-1556 ( $w t$, bay) as a reference. Due to the genome divergence between the EU1 and NA1 lineages, a high background was seen. For an explanation of graphs, see Additional file 3. A) When the genome contents of EU1 wt isolate P2363 and the NA1 reference were compared, copy number reduction was detected for several regions (red bars), which accompany increase in SNP allele ratios, suggesting P2363 is a mixture of monosomic and disomic nuclei. B) When EU1 nwt isolate P2346 and the reference were compared, increases (red bars) as well as decreases in the genome content were detected. Note that several scaffolds show large heterozygous SNP ratios while copy number changes in corresponding scaffolds are subtle. This may implicate a formation of $\mathrm{cnLOH}$. C) EU1 nwt isolate P2386 shows large SNP allele ratios in several scaffolds indicating the formation of $\mathrm{cnLOH}$ (red bars). These $\mathrm{cnLOH}$ scaffolds are, however, distinct from those observed in P2346. (PDF $561 \mathrm{~kb}$ )

Additional file 11: Illumina DNA sequencing summary. Sequencing conditions, facility names, obtained read numbers and genome depth are shown. (XLSX $43 \mathrm{~kb})$

\section{Abbreviations}

CCNV: chromosomal copy number variation; $\mathrm{cnLOH}$ : chromosomal number neutral loss of heterozygosity; GAP: growth acceleration phenotype; HIPD: host-induced phenotypic diversification; LOH: loss of heterozygosity; nwt: non-wild type; TE: transposable element; wt: wild type.

\section{Competing interests}

The authors declare that they have no competing interests.

\section{Authors' contributions}

TK, MG, DMR, EB, TS, JW, and CB conceived and designed the experiments. $\mathrm{TK}, \mathrm{MB}, \mathrm{KA}, \mathrm{EB}$, and TS conducted plant inoculation experiments. TK, MB, JW, and $C B$ assessed phenotypic changes. TK, MB, LMC, and CP prepared samples and conducted genome sequencing. TK, MB, LMC, CB, and JW analyzed the data. TK, DMR, MG, NJG, JW, and CB contributed reagents/ materials/analysis tools. TK, MG, DMR, and CB wrote the manuscript. All authors revised and approved the final manuscript.

\section{Acknowledgements}

We thank R. Jiang and S. Tripathy for sharing gene models and transposable elements in the $P$. ramorum genome; $S$. Kamoun for providing support for genome sequencing; J. Yuzon for reading an earlier version of the manuscript; C. Shoemaker and L. Diep for technical assistance; T. Parker for assistance on data analysis; V. Huffman, K. Suslow, K. Kosta, and W. Schweigkofler for supporting inoculation experiments. The authors gratefully acknowledge use of the services and facilities of the National Ornamentals Research Site at Dominican University of California. This project was funded by the United States Department of Agriculture - Agriculture Research Service, CRIS Project \# 5306-22000-014-00D to TK; the United States Department of Agriculture Farm Bill sections 10201 and 10007 to TK, DMR, and MG; the United States Department of Agriculture - Animal and Plant Health Inspection Service \#12-8130-0191-CA to TK, DMR, and MG; the United States Department of Agriculture - Forest Service, Sudden Oak Death Management and Monitoring in the Bay Area \#10-DG-11052021-214 and \#11-DG-11052021-111 to EB and TS; the Gordon and Betty Moore Foundation to DMR and MG; and the Midpeninsula Regional Open Space District to EB and TS.

\section{Author details}

${ }^{1}$ Crops Pathology and Genetics Research Unit, USDA Agricultural Research Service, Davis, California 95616, USA. ²Phytosphere Research, Vacaville, California 95687, USA. ${ }^{3}$ Department of Plant Pathology, University of California, Davis, California 95616, USA. ${ }^{4}$ Department of Plant Pathology, University of Florida, IFAS, Indian River Research and Education Center, Fort Pierce, Florida 34945, USA. ${ }^{5}$ Forest Research, Farnham, Surrey GU10 4LH, UK ${ }^{6}$ Horticultural Crops Research Laboratory, USDA Agricultural Research Service, Corvallis, Oregon 97330, USA. ${ }^{7}$ Department of Environmental Science, Policy, and Management, University of California, Berkeley, California 947020, USA. 


\section{Received: 11 February 2016 Accepted: 28 April 2016}

\section{Published online: 20 May 2016}

\section{References}

1. Davis M. Invasion biology. New York: Oxford University Press; 2009.

2. Brasier CM. Episodic selection as a force in fungal microevolution, with special reference to clonal speciation and hybrid introgression. Can J Bot. 1995;73:S1213-21.

3. Rando OJ, Verstrepen KJ. Timescales of genetic and epigenetic inheritance. Cell. 2007;128(4):655-68.

4. Goodwin SB, Sujkowski LS, Fry WE. Rapid evolution of pathogenicity within clonal lineages of the potato late blight disease fungus. Phytopathology. 1995;85(6):669-76.

5. Hüberli D, Tommerup IC, Dobrowolski MP, Calver MC, Hardy GESJ. Phenotypic variation in a clonal lineage of two Phytophthora cinnamomi populations from Western Australia. Mycol Res. 2001;105:1053-64.

6. Farrer RA, Henk DA, Garner TW, Balloux F, Woodhams DC, Fisher MC Chromosomal copy number variation, selection and uneven rates of recombination reveal cryptic genome diversity linked to pathogenicity. PLoS Genet. 2013;9(8):e1003703.

7. Selmecki A, Forche A, Berman J. Aneuploidy and isochromosome formation in drug-resistant Candida albicans. Science. 2006;313(5785):367-70.

8. Rancati G, Pavelka N, Fleharty B, Noll A, Trimble R, Walton K, Perera A, Staehling-Hampton K, Seidel CW, Li R. Aneuploidy underlies rapid adaptive evolution of yeast cells deprived of a conserved cytokinesis motor. Cell. 2008;135(5):879-93.

9. Kwon-Chung KJ, Chang YC. Aneuploidy and drug resistance in pathogenic fungi. PLoS Pathog. 2012;8(11):e1003022.

10. Rizzo DM, Garbelotto M, Davidson JM, Slaughter GW, Koike ST. Phytophthora ramorum as the cause of extensive mortality of Quercus spp. and Lithocarpus densiflorus in California. Plant Dis. 2002;86(3):205-14.

11. Brasier C, Webber J. Plant pathology sudden larch death. Nature. 2010; 466(7308):824-5

12. Werres S, Marwitz R, Veld WAMI, De Cock AWAM, Bonants PJM, De Weerdt M, Themann K, llieva E, Baayen RP. Phytophthora ramorum sp nov., a new pathogen on Rhododendron and Viburnum. Mycol Res. 2001;105:1155-65.

13. Parke JL, Linderman RG, Osterbauer NK, Griesbach JA. Detection of Phytophthora ramorum blight in Oregon nurseries and completion of Koch's postulates on Pieris, Rhododendron, Viburnum and Camellia. Plant Dis. 2004;88(1):87.

14. Goss EM, Carbone I, Grünwald NJ. Ancient isolation and independent evolution of the three clonal lineages of the exotic sudden oak death pathogen Phytophthora ramorum. Mol Ecol. 2009;18(6):1161-74.

15. Ivors K, Garbelotto M, Vries IDE, Ruyter-Spira C, Hekkert BT, Rosenzweig N, Bonants P. Microsatellite markers identify three lineages of Phytophthora ramorum in US nurseries, yet single lineages in US forest and European nursery populations. Mol Ecol. 2006;15(6):1493-505.

16. Grünwald NJ, Goss EM, Press CM. Phytophthora ramorum: a pathogen with a remarkably wide host range causing sudden oak death on oaks and ramorum blight on woody ornamentals. Mol Plant Pathol. 2008;9(6):729-40.

17. Van Poucke K, Franceschini S, Webber JF, Vercauteren A, Turner JA, Mccracken AR, Heungens K, Brasier CM. Discovery of a fourth evolutionary lineage of Phytophthora ramorum: EU2. Fungal Biol. 2012;116(11):1178-91.

18. Grünwald NJ, Goss EM, Ivors K, Garbelotto M, Martin FN, Prospero S, Hansen E, Bonants PJM, Hamelin RC, Chastagner G et al: Standardizing the nomenclature for clonal lineages of the sudden oak death pathogen, Phytophthora ramorum. Phytopathology. 2009;99(7):792-5.

19. Brasier C, Kirk S, Rose J. Differences in phenotypic stability and adaptive variation between the main European and American lineages of Phytophthora ramorum. In: 3rd Int IUFRO Work: 2006; Friesing, Germany. Farnham: Forest Research; 2006. p. 166-73.

20. Elliott M, Sumampong G, Varga A, Shamoun SF, James D, Masri S, Grünwald $\mathrm{NJ}$ : Phenotypic differences among three clonal lineages of Phytophthora ramorum. For Pathol. 2011:41(1):7-14

21. Kasuga T, Kozanitas M, Bui M, Hüberli D, Rizzo DM, Garbelotto M. Phenotypic diversification is associated with host-induced transposon derepression in the Sudden Oak Death pathogen Phytophthora ramorum. PLoS One. 2012;7(4):e34728.

22. Davidson JM, Wickland AC, Patterson HA, Falk KR, Rizzo DM. Transmission of Phytophthora ramorum in mixed-evergreen forest in California. Phytopathology. 2005;95(5):587-96.
23. Swiecki TJ, Bernhardt E. Evaluation of stem water potential and other tree and stand variables as risk factors for Phytophthora ramorum canker development in coast live oak. In: Proceedings in 5th Oak Symposium: Oaks in California's Changing Landscape: 2001. San Diego: USDA Forest Service; 2001. p. 787-9.

24. Callahan ME, Switzer WM, Matthews AL, Roberts BD, Heneine W, Folks TM, Sandstrom PA: Persistent zoonotic infection of a human with simian foamy virus in the absence of an intact orf-2 accessory gene. J Virol. 1999;73(11): 9619-24.

25. O'Fallon B. Population structure, levels of selection, and the evolution of intracellular symbionts. Evolution. 2008;62(2):361-73.

26. Swiecki TJ, Bernhardt E, Aram K, Rizzo MD, Kasuga T, Bui M. Phytophthora ramorum causes cryptic bole cankers in canyon live oak. Plant Health Prog. 2016;17(1):20-6.

27. Sionov E, Lee H, Chang YC, Kwon-Chung KJ. Cryptococcus neoformans overcomes stress of azole drugs by formation of disomy in specific multiple chromosomes. PLoS Pathog. 2010;6(4):e1000848.

28. Xi R, Hadjipanayis AG, Luquette LJ, Kim TM, Lee E, Zhang J, Johnson MD, Muzny DM, Wheeler DA, Gibbs RA et al: Copy number variation detection in whole-genome sequencing data using the Bayesian information criterion. Proc Natl Acad Sci U S A. 2011;108(46):E1128-36.

29. Tyler BM, Tripathy S, Zhang XM, Dehal P, Jiang RHY, Aerts A, Arredondo FD, Baxter L, Bensasson D, Beynon JL et al: Phytophthora genome sequences uncover evolutionary origins and mechanisms of pathogenesis. Science. 2006;313(5791):1261-6.

30. Sansome $\mathrm{E}$, Brasier CM, Griffin MJ. Chromosome size differences in Phytophthora palmivora, a pathogen of cocoa. Nature. 1975;255(5511):704-5

31. Sansome S, Brasier CM. Diploidy and chromosomal structural hybridity in Phytophthora infestans. Nature. 1973;241:344-5.

32. Brasier CM, Sansome E. Diploidy and gametangial meiosis in Phytophthora cinnamomi, Phytophthora infestans and Phytophthora drechsleri. T Brit Mycol Soc. 1975;65:49-65.

33. Mannaert A, Downing T, Imamura H, Dujardin JC. Adaptive mechanisms in pathogens: universal aneuploidy in Leishmania. Trends Parasitol. 2012;28(9):370-6.

34. Brasier C, Webber JF. Natural stem infection of Lawson cypress (Chamaecyparis lawsoniana) caused by Phytophthora ramorum. New Dis Report. 2012;25:26

35. Bartz SR, Rogel ME, Emerman M. Human immunodeficiency virus type 1 cell cycle control: Vpr is cytostatic and mediates G2 accumulation by a mechanism which differs from DNA damage checkpoint control. J Virol. 1996;70(4):2324-31.

36. Ben-Abdallah M, Sturny-Leclere A, Ave P, Louise A, Moyrand F, Weih F, Janbon G, Memet S: Fungal-induced cell cycle impairment, chromosome instability and apoptosis via differential activation of NF-kappaB. PLoS Pathog. 2012;8(3):e1002555.

37. Umeda M, Murata-Kamiya N, Saito Y, Ohba Y, Takahashi M, Hatakeyama M. Helicobacter pylori CagA causes mitotic impairment and induces chromosomal instability. J Biol Chem. 2009;284(33):22166-72.

38. Goodwin SB, Schneider RE, Fry WE. Use of Cellulose-Acetate Electrophoresis for Rapid Identification of Allozyme Genotypes of Phytophthora-Infestans. Plant Dis. 1995:79(11):1181-5.

39. Michelmore RW, Sansome ER. Cytological Studies of Heterothallism and Secondary Homothallism in Bremia-Lactucae. T Brit Mycol Soc. 1982;79(Oct):291-7.

40. Tyler BM, Forster H, Coffey MD. Inheritance of avirulence factors and restriction-fragment-length-polymorphism markers in outcrosses of the oomycete Phytophthora sojae. Mol Plant-Microbe Interact. 1995;8(4):515-23.

41. Mortimer AM, Shaw DS, Sansome ER. Genetical studies of secondary homothallism in Phytophthora drechsleri. Arch Microbiol. 1977;111(3):255-9.

42. Carter DA, Buck KW, Archer SA, Van der Lee T, Shattock RC, Shaw DS. The detection of nonhybrid, trisomic, and triploid offspring in sexual progeny of a mating of Phytophthora infestans. Fungal Genet Biol. 1999:26(3):198-208.

43. Vercauteren A, Boutet $X$, D'hondt L, Van Bockstaele E, Maes M, Leus L, Chandelier A, Heungens K: Aberrant genome size and instability of Phytophthora ramorum progenies. Fungal Genet Biol. 2011;48(5):537-43.

44. Lamour KH, Mudge J, Gobena D, Hurtado-Gonzales OP, Schmutz J, Kuo A, Miller NA, Rice BJ, Raffaele S, Cano LM et al. Genome sequencing and mapping reveal loss of heterozygosity as a mechanism for rapid adaptation in the vegetable pathogen Phytophthora capsici. Mol Plant Microbe Interact. 2012;25(10):1350-60.

45. Mantikou E, Wong KM, Repping S, Mastenbroek S. Molecular origin of mitotic aneuploidies in preimplantation embryos. Bba-Mol Basis Dis. 2012; 1822(12):1921-30 
46. Arlt MF, Durkin SG, Ragland RL, Glover TW. Common fragile sites as targets for chromosome rearrangements. DNA Repair. 2006;5(9-10):1126-35.

47. Durkin SG, Glover TW. Chromosome fragile sites. Annu Rev Genet. 2007;41:169-92.

48. Selmecki AM, Maruvka YE, Richmond PA, Guillet M, Shoresh N, Sorenson AL, De S, Kishony R, Michor F, Dowell R et al: Polyploidy can drive rapid adaptation in yeast. Nature. 2015;519(7543):349-52

49. Doring HP, Nelsen-Salz B, Garber R, Tillmann E. Double Ds elements are involved in specific chromosome breakage. Mol Gen Genet. 1989;219(1-2):299-305.

50. Ralston E, English J, Dooner HK. Chromosome-breaking structure in maize involving a fractured Ac element. Proc Natl Acad Sci U S A. 1989;86(23):9451-5.

51. St Charles J, Petes TD. High-resolution mapping of spontaneous mitotic recombination hotspots on the $1.1 \mathrm{Mb}$ arm of yeast chromosome IV. PLoS Genet. 2013:9(4):e1003434.

52. Sansome E. Polyploidy and induced gametangial formation in British Isolates of Phytophthora infestans. J Gen Microbiol. 1977;99:311-6.

53. Catal M, King L, Tumbalam P, Wiriyajitsomboon P, Kirk WW, Adams GC. Heterokaryotic nuclear conditions and a heterogeneous nuclear population are observed by flow cytometry in Phytophthora infestans. Cytometry A. 2010;77(8):769-75.

54. Thorburn RR, Gonzalez C, Brar GA, Christen S, Carlile TM, Ingolia NT, Sauer U, Weissman JS, Amon A: Aneuploid yeast strains exhibit defects in cell growth and passage through START. Mol Biol Cell. 2013;24(9):1274-89.

55. Torres EM, Williams BR, Amon A. Aneuploidy: cells losing their balance. Genetics. 2008;179(2):737-46.

56. Gerstein AC, Kuzmin A, Otto SP. Loss-of-heterozygosity facilitates passage through Haldane's sieve for Saccharomyces cerevisiae undergoing adaptation. Nat Commun. 2014;5.

57. Sheltzer JM, Amon A. The aneuploidy paradox: costs and benefits of an incorrect karyotype. Trends Genet. 2011;27(11):446-53.

58. Brasier C. The rise of the hybrid fungi. Nature. 2000;405(6783):134-5.

59. Swiecki TJ, Bernhardt E. Long-term trends in coast live oak and tanoak stands affected by Phytophthora ramorum canker (sudden oak death). In: Sudden Oak Death Fourth Science Symposium: 2010. Albany: USDA Forest Service; 2010. p. 207-9.

60. Nagle AM, McPherson BA, Wood DL, Bonello P, Garbelotto M. Does phloem phenolic chemistry contribute to coast live oak resistance to Phytophthora ramorum? Phytopathology. 2009;99(6):S92

61. Nagle AM, McPherson BA, Wood DL, Garbelotto M, Bonello P. Relationship between field resistance to Phytophthora ramorum and constitutive phenolic chemistry of coast live oak. For Pathol 2011. 10.1111/j.1439-0329. 2010.00703.x.

62. Du TC, Shupe TF, Hse CY. Antifungal activities of three supercritical fluid extracted cedar oils. Holzforschung. 2011;65(2):277-84.

63. Pala-Paul J, Usano-Alemany J, Granda E, Soria AC. Antifungal and antibacterial activity of the essential oil of Chamaecyparis lawsoniana from Spain. Nat Prod Commun. 2012;7(10):1383-6.

64. Sansome E, Harris BJ. Use of camphor-induced polyploidy to determine place of meiosis in fungi. Nature. 1962;196(4851):291-2.

65. English AC, Richards S, Han Y, Wang M, Vee V, Qu J, Qin X, Muzny DM, Reid JG, Worley KC et al: Mind the gap: upgrading genomes with Pacific Biosciences RS long-read sequencing technology. PLoS One. 2012;7(11):e47768.

66. Kim J, Larkin DM, Cai Q, Asan, Zhang Y, Ge RL, Auvil L, Capitanu B, Zhang G, Lewin HA et al: Reference-assisted chromosome assembly. Proc Natl Acad Sci U S A. 2013;110(5):1785-90.

67. Englander L, Roth LF. Interaction of light and sterol on sporangium and chlamydospore production by Phytophthora lateralis. Phytopathology. 1980; 70(7):650-4.

68. Tsao PH, Ocana G. Selective isolation of species of Phytophthora from natural soils on an improved antibiotic medium. Nature. 1969:223(5206):636-8.

69. McCluskey K, Wiest A, Plamann M. The Fungal Genetics Stock Center: a repository for 50 years of fungal genetics research. J Biosci. 2010;35(1):119-26.

70. Kasuga T, Bui M. Evaluation of automated cell disruptor methods for oomycetous and ascomycetous model organisms. Fungal Genet Report. 2011;58:4-13.

71. Irizarry RA, Hobbs B, Collin F, Beazer-Barclay YD, Antonellis KJ, Scherf U, Speed TP: Exploration, normalization, and summaries of high density oligonucleotide array probe level data. Biostatistics. 2003;4(2):249-64.

72. Brazma A, Hingamp P, Quackenbush J, Sherlock G, Spellman P, Stoeckert C, Aach J, Ansorge W, Ball CA, Causton HC et al: Minimum information about a microarray experiment (MIAME) - toward standards for microarray data. Nat Genet. 2001;29(4):365-71.
73. Isolation of genomic DNA from plants and filamentous fungi using the QIAGEN ${ }^{\circledR}$ Genomic-tip. [http://www.qiagen.com/resources/ resourcedetail?id=cb2ac658-8d66-43f0-968e-7bb0ea2c402a\&lang=en]

74. Champouret N, Kamoun S. An improved protocol for the protoplast method of stable DNA transformation of Phytophthora infestans. 2004

75. Judelson HS, Tyler BM, Michelmore RW. Transformation of the oomycete pathogen, Phytophthora infestans. Mol Plant Microbe Interact. 1991;4(6):602-7.

76. Buffalo V. Scythe - A Bayesian adapter trimmer In: version 0.993 BETA edn. 2011.

77. Joshi NA, Fass JN. Sickle: A sliding-window, adaptive, quality-based trimming tool for FastQ files In: Version 1.29 edn. 2011.

78. Li H, Durbin R. Fast and accurate short read alignment with Burrows-Wheeler transform. Bioinformatics. 2009;25(14):1754-60.

79. Li H, Handsaker B, Wysoker A, Fennell T, Ruan J, Homer N, Marth G, Abecasis G, Durbin R: The Sequence Alignment/Map format and SAMtools. Bioinformatics. 2009:25(16):2078-9.

80. Li H. A statistical framework for SNP calling, mutation discovery, association mapping and population genetical parameter estimation from sequencing data. Bioinformatics. 2011;27(21):2987-93.

81. Thorvaldsdottir H, Robinson JT, Mesirov JP. Integrative Genomics Viewer (IGV): high-performance genomics data visualization and exploration. Brief Bioinform. 2013;14(2):178-92.

82. Tripathy S, Deo T, Tyler BM. Oomycete Transcriptomics Database: a resource for oomycete transcriptomes. BMC Genomics. 2012;13:303.

\section{Submit your next manuscript to BioMed Central and we will help you at every step:}

- We accept pre-submission inquiries

- Our selector tool helps you to find the most relevant journal

- We provide round the clock customer support

- Convenient online submission

- Thorough peer review

- Inclusion in PubMed and all major indexing services

- Maximum visibility for your research

Submit your manuscript at www.biomedcentral.com/submit
BioMed Central 